\title{
CHARACTERISTICS OF AUTOCLAVE AND IN-REACTOR NODULAR CORROSION OF ZIRCALOYS
}

ANL $/ C P--69633$

\author{
Y. H. Jeong and K. S. Rheem \\ Korea Atomic Energy Research Institute \\ Daeduk-Danji, Choong-Nam \\ Republic of Korea
}

DE91 013600

\section{and}

\author{
H. M. Chung \\ Materials and Components Technology Division \\ Argonne National Laboratory \\ Argonne, Illinois 60439 USA
}

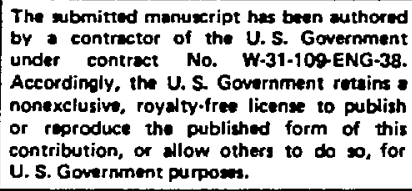

The submitted manuxeript has been authored by contractor of the U.S. Government under contrace No. W-31-109ENG-38. Accordingly. the U.S. Government retuins : nonexclusive, royalty-free license to publish

or reproduce the published form of this or reproduce the published form of this contribution, or wlow others to do so, for U. S. Government purpows.

November 1990

\section{DISCLAIMER}

\begin{abstract}
This report was prepared as an account of work sponsored by an agency of the United States Government. Neither the United States Government nor any agency thereof, nor any of their employees, makes any warranty, express or implied, or assumes any legal liability or responsibility for the accuracy, completeness, or usefulness of any information, apparatus, product, or process disclosed, or represents that its use would not infringe privately owned rights. Reference herein to any specific commercial product, process, or service by trade name, trademark, manufacturer, or otherwise does not necessarily constitute or imply its endorsement, recommendation, or favoring by the United States Government or any agency thereof. The views and opinions of authors expressed herein do not necessarily state or reflect those of the United States Government or any agency thereof.
\end{abstract}

Paper presented at the Ninth International Symposium on Zirconium in the Nuclear Industry, November 5-8, 1990, Kobe, Japan. 


\title{
CHARACTERISTICS OF AUTOCLAVE AND IN-REACTOR NODILAR CORROSION OF ZIRCALOYS
}

\author{
Y. H. Jeong and K. S. Rheem \\ Korea Atomic Energy Research Institute \\ Daeduk-Danji,' Choong-Nam \\ Republic of Korea \\ and \\ H. M. Chung \\ Materials and Components Technology Division \\ Argonne National Laboratory \\ Argonne, Illinois 60439, USA
}

\begin{abstract}
Nodular corrosion characteristics of recrystallized Zircaloy-4 were investigated in static autoclave tests at $500^{\circ} \mathrm{C}$ and $10.3 \mathrm{MPa}$. The roles of annealing temperature, cooling rate after beta-treating at $1050^{\circ} \mathrm{C}$, cold work, and surface treatment in corrosion tests were correlated with the results of microstructural characterization by scanning and transmission electron microscopies. A good correlation was obtained between average size of intermetallic precipitates and weight gain, in contrast to nodule coverage and nodule number density. These results could be best explained by the hypothesis that nodules nucleate in local regions that are depleted of $\mathrm{Fe}$ and $\mathrm{Cr}$ alloying elements. Some observations were inconsistent with the premise that nodules nucleate on or near intermetallic precipitates. Nodular corrosion characteristics and microstructures of commercial Zircaloy-2 cladding of fuel and gadolinia rods, obtained from several BWRs after burnup of 11-30 $\mathrm{MWd} / \mathrm{kgU}$, were also examined. Partial amorphization of intermetallic precipitates in BWR
\end{abstract}


Zircaloy-2, and virtual dissolution and in an extreme case spinodal-like fluctuations of dissolved alloying elements in PWR Zircaloy-4 cladding were observed. Occurrence of nodular oxidation of Zircaloy-2 in BWRs could best be correlated to average size of intermetallic precipitates before irradiation and to fuel cladding operating temperature. For an intermetallic size range of $250-700 \mathrm{~nm}$, nodular oxides were observed at $288^{\circ} \mathrm{C}$, but only thick uniform oxide was observed at $307^{\circ} \mathrm{C}$. For extendedburnup operation, increased precipitation of hydrides, suboxides, and small oxide particles, apparently formed via an irradiation-induced process, is expected near the metal/oxide boundary and results in more pronounced microcracking along the metal/oxide boundary. In addition to its association with metal/oxide boundary temperature, which increases for increasing oxide thickness, boundary microcracking may be associated with accelerated corrosion of extended-burnup fuel of $>45 \mathrm{MWd} / \mathrm{kgU}$ (rodaverage burnup).

KEY WORDS: Zircaloys, nodular corrosion, intermetallic precipitates, hydride, irradiation, amorphization, irradiation-induced precipitation, extended-burnup

Because of present industry trends toward extended burnup and increased operating temperatures in LWR fuels, improved corrosion behavior of Zircaloy fuel cladding is an important objective. For BWRs and PWRs, nodular and uniform accelerated corrosion, respectively, remain as primary fuel performance concerns. The former type of accelerated corrosion has been investigated extensively in recent years, ${ }^{1-26}$ primarily on Zircaloy-2 but also on Zircaloy-4,1,6-8,13,19,21,23,24 $\mathrm{Zr}-2.5 \mathrm{Nb}, 26$ and other $\mathrm{Zr}$-based alloys. ${ }^{3}$ In-reactor nodular corrosion is usually simulated in 
autoclave tests at $490-530^{\circ} \mathrm{C}$, whereas the uniform corrosion has been investigated at $350-400^{\circ} \mathrm{C}$. From these studies, it has been established that nodular corrosion is strongly influenced by microstructural and microchemical variations in Zircaloys, especially by the size and distribution of the intermetallic precipitates that are governed by thermomechanical treatments during tube manufacturing. In general, large $\mathrm{Zr}(\mathrm{Fe}, \mathrm{Cr})_{2}$ and $\mathrm{Zr}_{2}(\mathrm{Fe}, \mathrm{Ni})$ precipitates in Zircaloy-2, and $\mathrm{Zr}(\mathrm{Fe}, \mathrm{Cr})_{2}$ in Zircaloy-4, are conducive to higher susceptibility to nodular corrosion. Under reactor operating conditions, neutron irradiation induces amorphization and dissolution of these precipitates and modifies the size, number density, and composition of the precipitates and the surrounding Zircaloy matrix.27-32 In-service microstructural modification appears to be sensitive to irradiation temperature, flux, and fluence: both size and density decrease with increased neutron fluence at $290-300^{\circ} \mathrm{C}$, but the average size increases with fluence at $340-390^{\circ} \mathrm{C} .31$ Microstructural modification could influence corrosion properties, in particular corrosion during an extended-burnup operation, because of redistribution of the existing precipitates, secondary precipitation from the matrix, or higher or lower concentrations of interstitial and substitutional solutes. However, for irradiated fuel cladding, investigators have not yet reached a consensus on precipitate identification, long-term microstructural evolution, or the effects of size and distribution on nodular corrosion behavior.

Primarily on the basis of observations from autoclave studies, two mechanisms for nodule nucleation have been considered by most investigators. One mechanism stipulates that nodules nucleate on or around intermetallic precipitates themselves, 5 while the second 
mechanism states that nucleation occurs in local regions away from precipitates, which are depleted of the alloying elements.3,11,25 However, neither of these mechanisms, which are mutually exclusive in terms of the roles of $\mathrm{Fe}, \mathrm{Cr}$, and $\mathrm{Ni}$ atoms, has been șupported by clear and unambiguous experimental evidence. In contrast to nodular corrosion of Zircaloy-2, the opposite characteristics have been reported for uniform corrosion of Zircaloy-4. That is, uniform corrosion rates of Zircaloy-4, in both autoclave tests and PWR fuel rods, were higher for tubes in which the accumulated annealing parameter (and hence the size of the precipitates) was smaller.7.17 These observations have been at least partially, confirmed qualitatively in recent autoclave tests, although no clear correlation was observed for the intermediate range of precipitate size where a sharp transition in corrosion rate is found.2,14 At present, it is difficult to understand the seemingly inconsistent effects for Zircaloy-4, although other important variables such as coolant chemistry (oxygenated or hydrogenated) must be considered, and details of the heat treatment (recrystallization, stress-relieving, beta-quenching), microstructural and microchemical variations, and irradiation conditions $7,14,17$ must be carefully compared. In the present investigation, characteristics of nodular corrosion in autoclave and reactor specimens were examined comparatively to elucidate roles of salient microstructural features of irradiated and unirradiated materials. The study was conducted in parallel with an investigation of autoclave and in-reactor behavior of uniform accelerated corrosion of Zircaloy-4.

\section{Experimental Procedure}

\section{Autoclave Corrosion}


Autoclave corrosion tests were conducted primarily on Zircaloy-4, although several scoping tests on sponge-grade $\mathrm{Zr}$ and $\mathrm{Zr}-2.5 \mathrm{Nb}$ were also performed. The 2.1-mm-thick sheets of recrystallized Zircaloy-4 contained $1.49 \mathrm{Sn}, 0.20 \mathrm{Fe}, 0.10 \mathrm{Cr}, 0.145 \mathrm{O}$ (in wt.\%) and impurity elements of $180 \mathrm{C}$, $62 \mathrm{Hf},<5 \mathrm{H},<35 \mathrm{Ni}, 78 \mathrm{Si}$, and $1.8 \mathrm{U}$ (in wt. ppm). Corrosion tests were conducted in a static autoclave at $500^{\circ} \mathrm{C}$ and $10.3 \mathrm{MPa}$ for up to $50 \mathrm{~h}$. Effects of annealing temperature $\left(700,800,900\right.$, and $1050^{\circ} \mathrm{C}$ ), cold work $(30,50$, and $80 \%$ ), and $\beta$-quench cooling rate (furnace-cool, air-cool, and water- quench) were examined. Effects of surface treatments after coarse (120 grit) and fine (600 grit) grinding, polishing, and pickling (in a solution of $3 \mathrm{HF}, 40 \mathrm{HNO}_{3}$, and $57 \mathrm{H}_{2} \mathrm{O}$ (in vol.\%) were also examined. After the corrosion tests, fraction of surface nodule coverage (by optical microscopy), weight gain, and particle distribution (by SEM) were determined for each specimen.

In-Reactor Corrosion

In-reactor corrosion properties were measured on Zircaloy-2 and -4 cladding of spent fuel rods obtained from three BWRs and one PWR, as well as on absorber rods containing 3 wt.\% $\mathrm{Gd}_{2} \mathrm{O}_{3}$ from one BWR. Fuel burnup and neutron fluence were in the range of 11-30 $\mathrm{MWd} / \mathrm{kgU}$ and 1.6-4.4 $\times 10^{21} \mathrm{ncm}^{-2}$ (E >0.1 MeV), respectively. Waterside oxide morphology and layer thicknesses of polished and etched metallographic specimens of defueled rod sections were examined. These results are summarized in Table 1. Before the fuel rod sections were cut, eddycurrent inspection was conducted to ensure that the cladding contained no defects. All of the rods were free from defects, except for the gadolinia absorber rod from BWR-D (Table 1). The gadolinia rod showed indications 
of pinhole failure by pellet/cladding interaction. A metallographic section of the gadolinia rod was then cut through the axial location of the pinhole failure. The pin-hole failure was confirmed from the metallorgraphic examination. Cladding from some of the BWRs was annealed and recrystallized, as shown in Table 1.

\section{Microstructural Characterization}

Microstructures of the autoclave and fuel cladding specimens were analyzed by SEM and TEM. SEM characterization of intermetallic precipitate size and distribution was found to be inaccurate because of limits in resolution and the frequent presence of artifact particles picked up during polishing. However, in TEM, intermetallic precipitates could be discerned from artifact phases through dark-field imaging, tilting, or stereo examinations. The TEM disks were jet-thinned in electrolyte solutions of perchloric acid, butylcellosolve, and methanol (volume ratio 2:12:30) maintained at $-70^{\circ} \mathrm{C}$. The foil planes of the midwall TEM specimens were nearly perpendicular to the thickness direction. The thin-foil specimens were then examined in a JEOL scanning transmission electron microscope (STEM) or in a Kratos/AEI-EM7 high-voltage electron microscope, which operated at 0.1 and $1 \mathrm{MeV}$, respectively. To determine the size distribution, typically 15 to 20 dark-field images of the intact or partially amcrphized intermetallic precipitates were obtained from three to five thin-foil specimens. Care was required to discern images of surface hydrides (size in the range of 20-300 $\mathrm{nm}$ ) and other artifacts (namely, hydrocarbon film, organic vapor condensates, and remnants of masking solutions that frequently form during specimen preparation and examination) from those of intermetallic precipitates. Without tilting or 
dark-field imaging, the bright-field images of some of these artifacts could be mistaken for those of the intermetallic precipitates.

\section{Results and Discussion of Autoclave Corrosion}

Scoping tests on Zircaloy-4, sponge $\mathrm{Zr}$, and $\mathrm{Zr}-2.5 \mathrm{Nb}$, conducted at $500^{\circ} \mathrm{C}$ for $24 \mathrm{~h}$, illustrate the relative susceptibility of the materials to nodular corrosion (Fig. 1). Both as-received and beta-quenched $\mathrm{Zr}-2.5 \mathrm{Nb}$ did not exhibit nodular corrosion, in contrast to significant nodule formation on $\mathrm{Zr}$ and Zircaloy-4 specimens. The superior resistance of $\mathrm{Zr}-2.5 \mathrm{Nb}$ is consistent with results of Bentley. ${ }^{33}$ The sequence of the nodule formation on Zircaloy-4 is shown in Fig. 1B. From the figure, it can be deduced that nodules form at a relatively early stage, i.e., between 2 and $6 \mathrm{~h}$.

\section{Effect of Annealing Temperature}

Effects of annealing (for $30 \mathrm{~min}$ at $700,800,900$, and $1050^{\circ} \mathrm{C}$, followed by water quenching) on nodule coverage and weight gain are shown in Figs. 2A and 2B, respectively. The optical micrographs showing nodule distributions in the two figures correspond to corrosion for 24 and $48 \mathrm{~h}$, respectively. A comparison of the nodule distributions in the two figures indicates that number densities of nodules are similar for the 24- and 48-h exposures but that only nodule growth occurred during the longer exposure. Although the effect of annealing at $700^{\circ} \mathrm{C}$ is insignificant, drastic improvements in nodular-corrosion resistance are evident after annealing at 800,900 , or $1050^{\circ} \mathrm{C}$, an observation similar to those of others (e.g., Ref. 25). However, in contrast to the present results, the effect of $800^{\circ} \mathrm{C}$ annealing was found in Refs. 22 and 25 to be negligible for Zircaloy-4. In the investigation by Cheng and Adamson, 25 significant improvement in 
corrosion following annealing at 700,750 , and $800^{\circ} \mathrm{C}$ occurred only for Zircaloy-2 specimens; this was attributed to the postulated increase in matrix Ni content following the high- $\alpha$ anneals. A similar difference in the effect of high- $\alpha$ anneals on the susceptibilities of Zircaloy-2 and -4 was not observed in the study by Garzarolli et al., in which the specimens were annealed only shortly before quenching. 22 During the short annealing time, precipitate dissolution or solute atom redistribution was probably insignificant. It is also probable that the stabilities of the $\alpha-\mathrm{Zr}$ and intermetallic phases may be different for slightly different materials used in the three investigations at $800^{\circ} \mathrm{C}$, a temperature very close to the nominal $\alpha / \beta$ phase boundary. These considerations may rationalize the difference between the present result and that of Ref. 25 for the effect of $800^{\circ} \mathrm{C}$-annealing on Zircaloy-4, as well as the difference between results obtained for Zircaloy-2 in Refs. 22 and 25.

TEM examination of the specimens of Fig. 2 showed that the $\mathrm{Zr}(\mathrm{Fe}, \mathrm{Cr})_{2}$ precipitates remained more or less intact after the $700^{\circ} \mathrm{C}$ annealing and that they dissolved completely at $1050^{\circ} \mathrm{C}$, as expected. Precipitates in specimens annealed at $800^{\circ} \mathrm{C}$ were significantly smaller than those in the as-received specimen, but the number density of the precipitates was similar in both materials. This indicates that partial dissolution of the precipitates occurred during the anneal. Most, but not all, of the precipitates dissolved after annealing at $900^{\circ} \mathrm{C}$. A few dislocations and grain-boundary hydrides were also observed in the specimens annealed at 800 and $900^{\circ} \mathrm{C}$. Apparently, the grain boundary hydrides formed during the laboratory annealing treatments. Figure 3 shows examples of TEM 
morphologies of the $\mathrm{Zr}(\mathrm{Fe}, \mathrm{Cr})_{2}$ precipitates observed in the Zircaloy-4 specimens after the various annealing, cooling, and cold-rolling treatments.

The partial dissolution of precipitates during $800^{\circ} \mathrm{C}$ annealing is somewhat surprising in view of the dissolution temperatures $>860^{\circ} \mathrm{C}$, reported in Ref. 34 for intermetallics in Zircaloy-2. However, results of a recent investigation on a $\mathrm{Zr}-\mathrm{Sn}-\mathrm{Fe}-\mathrm{Cr}-\mathrm{O}$ alloy whose composition was similar to that of the present specimens indicate that the intermetallics are unstable at $>810^{\circ} \mathrm{C}$ in Zircaloy-4.35 The same study also showed that the boundary temperature for dissolution of intermetallics varies for different levels of $\mathrm{Fe}$ and $\mathrm{Cr}$. It is also possible that precipitate stability at $800^{\circ} \mathrm{C}$ may have been influenced by the significant uptake of hydrogen which is a $\beta$-stabilizer. Therefore, it seems that the boundary temperature for dissolution of $\mathrm{Zr}(\mathrm{Fe}, \mathrm{Cr})_{2}$ precipitates in the present material was lower than that of the Zircaloy-4 of Ref. 25. The significantly reduced susceptibility to nodular corrosion after annealing at $800^{\circ} \mathrm{C}$, as well as at 900 and $1050^{\circ} \mathrm{C}$ appears, to be consistent with partial or complete dissolution of $\mathrm{Zr}(\mathrm{Fe}, \mathrm{Cr})_{2}$ precipitates. Because the number density of the precipitates was similar before and after the $800^{\circ} \mathrm{C}$ annealing, the significantly lower susceptibility appears to be inconsistent with a mechanism in which nodules nucleate on or around the precipitates. Rather, it seems consistent with a mechanism whereby increased levels of $\mathrm{Fe}$ and $\mathrm{Cr}$ in the matrix, accompanied by partial dissolution of the precipitates, suppressed nodule nucleation.

In contrast to the results of this study and those reported in Refs. 22 and 25 , annealing near $750^{\circ} \mathrm{C}$ has been reported as extremely deleterious for corrosion of two lots of Zircaloy-2, whereas annealing at 675,800 , and $850^{\circ} \mathrm{C}$ appeared to be beneficial for one lot (standard cladding), and more 
or less ineffective for another lot (beta-quenched).20 The deleterious effect of $750^{\circ} \mathrm{C}$ annealing (in vacuum for $2 \mathrm{~h}$, followed by furnace cooling) is not clearly understood although a distribution of very coarse (up to $2000 \mathrm{~nm}$ ) intermetallics was observed in the test specimens. Before the annealing treatment, the Zircaloy-2 specimens were stabilized at $600^{\circ} \mathrm{C}$ and cold worked to $70-80 \%$. A deleterious effect of $80 \%$ cold work (without annealing) on corrosion at $500^{\circ} \mathrm{C}$ was found in this study. Thus, the results of Ref. 20 may have been influenced by the severe cold work as well.

\section{Effect of Cooling Raie}

The effect of cooling rate (after $\beta$-phase annealing at $1050^{\circ} \mathrm{C}$ ) on nodule coverage and weight gain is shown in Fig. 4. Air cooling or water quenching after the $\beta$-anneal virtually suppresses nodule formation. Furnace cooling of $\beta$-annealed specimens at a rate of $0.05^{\circ} \mathrm{C} / \mathrm{s}$ resulted in a greater susceptibility (i.e., nodule coverage) than that of as-received material (Fig. 4A), although the weight gain was similar (Fig. 4B). As in the case of Fig. 2, nodule number densities in the optical micrographs of Figs. $4 \mathrm{~A}$ and $4 \mathrm{~B}$, corresponding to 24 and $48 \mathrm{~h}$ corrosion, respectively, are similar; this indicates that no additional nodules nucleated during the longer exposure. Previous investigations 6,22 of the effects of cooling rate on weight gain are consistent with the results in Fig. 4B, although similar data on nodule coverage were not reported.

TEM examination of several thin-foil specimens of the air-cooled and water-quenched material showed that reprecipitation of intermetallics was negligible during cooling (Fig. 3); SEM examination, however, showed a limited amount of precipitates, primarily on the boundaries of 
Widmannstaetten structure of the transformed $\beta$ phase. Some of the boundary precipitates observed by SEM were identified by dark-field examination in TEM as either hydrides or polishing artifacts rather than bulk intermetallics. Thus, the virtual suppression of nodule nucleation seems to be consistent with supersaturation of the $\mathrm{Fe}$ and $\mathrm{Cr}$ solutes during fast cooling.

In contrast to fast cooling, slow furnace cooling resulted in nodule coverage approximately twice as great as in the as-received material. A relative comparison of the data on nodule coverage and weight gain for the as-received and the beta-treated and furnace-cooled materials shows that a higher number density of nodules formed in the latter material than in the former. TEM dark-field imaging showed that the precipitates in the latter were several times smaller than those in the former (average size 400-420 nm; see Fig. 3). In the furnace-cooled material, very fine intermetallics approximately $20-50 \mathrm{~nm}$ in size were present in high density along with the larger, readily visible precipitates of $100-150 \mathrm{~nm}$ in size (Fig. 3). The very fine precipitates were not observed in either the air-cooled or water-quenched specimens. However, despite the smaller average size, nodule coverage was higher for the furnace-cooled material, which is in contrast to the observation in Fig. 2. It seems that an argument solely based on the relative size of the intermetallics cannot explain the relative nodule coverage observed for the furnace-cooled and as-received materials.

In addition to precipitation of intermetallics such as $\mathrm{Zr}_{4}(\mathrm{Fe}, \mathrm{Cr})$ or $\mathrm{Zr}(\mathrm{Fe}, \mathrm{Cr})_{2}$ during cooling, ${ }^{32}$ redistribution of solute atoms such as $\mathrm{Fe}, \mathrm{Cr}, \mathrm{O}$, and $\mathrm{H}$ is known to be significant, particularly during a slow transformation 
from the $\beta$ to the $\alpha$ phase. $\mathrm{Fe}, 36 \mathrm{Cr}, 36 \mathrm{Ni}, 36$ and $\mathrm{H}$ (beta stabilizers) diffuse toward the boundaries of the relatively thick lamellar structure that has a "lenticular-type" morphology, whereas $\mathrm{Sn}^{36}$ and $\mathrm{O}^{37}(\alpha$ stabilizers) diffuse in the opposite direction. The redistribution of these elements, therefore, is expected to produce local regions that are depleted of $\mathrm{Fe}$ and $\mathrm{Cr}$ in the present furnace-cooled specimens. Redistribution of $\mathrm{Sn}$ and $\mathrm{Ni}$ is usually less significant. 36 This localized depletion of $\mathrm{Fe}$ and $\mathrm{Cr}$, which is similar in magnitude to local depletion via precipitation of $\mathrm{Zr}_{4}(\mathrm{Fe}, \mathrm{Cr})$ or $\mathrm{Zr}(\mathrm{Fe}, \mathrm{Cr})_{2}$ intermetallics, will augment the localized depletion via the latter process during slow cooling from $1050^{\circ} \mathrm{C}$. Therefore, nodule nucleation is likely to be more pronounced in the furnace-cooled material than in the as-received material. Under conditions of fast cooling or cooling from a low alphabeta-phase temperature (e.g., $900^{\circ} \mathrm{C}$ ), these processes will be relatively insignificant. These observations seem to be consistent with a nucleation mechanism based on $\mathrm{Fe} / \mathrm{Cr}$-depleted local regions, 25 but are inconsistent with a mechanism based on intermetalics as nucleation sites. 5

\section{Effect of Cold Work}

The effect of cold work (i.e., thickness reduction of 30,50 , and $80 \%$ ) on nodule coverage and weight gain is shown in Fig. 5. Distributions of nodules observed after corrosion at $500^{\circ} \mathrm{C}$ for $24 \mathrm{~h}$ are shown in Fig. 5A. In Fig. 5B, TEM images of typical dislocation cell structures formed by the cold work are also shown. The 30 and $50 \%$ cold work produced less nodule coverage and weight gain. However, susceptibility to nodular corrosion increased significantly for specimens cold worked to $80 \%$. Specimens cold worked to $30 \%$ exhibited minimum susceptibility. TEM examination 
showed that the size, morphology, and distribution of the intermetallic precipitates did not change because of the cold work (Fig. 3).

It is not clear why susceptibility decreased significantly for the $30-50 \%$ cold work levels. One possible explanation can be advanced on the basis of the effect of strain aging. Strain aging of $\mathrm{Zr}, 38 \mathrm{Zr}$ alloys, $39 \mathrm{Zr}-\mathrm{O}$ alloys, 40 Zircaloy-2,41-43 and Zircaloy-443 has been reported in the temperature range of $150-750^{\circ} \mathrm{C}$. Strain aging at $250-330^{\circ} \mathrm{C}$ is generally attributed to the interaction of oxygen with dislocations, $40-42$ whereas a similar interaction of $\mathrm{Sn}$ has been suspected for the strain aging at $750^{\circ} \mathrm{C} .43$ Strain aging at $450-500^{\circ} \mathrm{C}$ has been attributed to $\mathrm{Fe} .39$ In view of this information, an interaction of $\mathrm{Fe}$ solute atoms with dislocations or dislocation entanglements in the cold-worked specimens is likely to occur during the $500^{\circ} \mathrm{C}$ corrosion tests. Therefore, an optimum distribution of dislocations may actually help reduce local variations in $\mathrm{Fe}$ content in some cold-worked specimens (e.g., the $30 \%$ cold-worked specimen), thereby reducing the number density of nodule nucleation sites. When cold work is too severe, e.g., $80 \%$, the effect of excessive residual stress may be predominant, resulting in more significant nodule nucleation. Although this should be considered only as a possible explanation, further investigation of the effect of cold work is warranted, e.g., on Zircaloy-4 containing low Fe.

\section{Effect of Surface Treatment}

The effect of various surface treatments, i.e., coarse- and fine-grinding, polishing, and pickling, is shown in Fig. 6. Weight gain (after $24 \mathrm{~h}$ corrosion) decreased in order due to coarse-grinding, fine-grinding, and 
polishing (from 1100 to $600 \mathrm{mg} / \mathrm{dm}^{2}$, compared to $800 \mathrm{mg} / \mathrm{dm}^{2}$ for an asreceived specimen), indicating a significant effect due to surface roughness and surface residual stress. However, the effect of surface treatment on nodule number density was insignificant, although a slight difference in total nodule coverage was noticed.

Although exceptions were noted in terms of nodule number density (e.g., the results in Fig. 4 on furnace cooled specimens and in Fig. 5 on the effect of cold work) the weight-gain data obtained from the autoclave tests could be correlated with the average size of intermetallic precipitates (Fig. 7). Qualitatively, this is consistent with the results in previous studies on Zircaloy-29,17,22,25 and Zircaloy-4.17,22,24,25

\section{Results and Discussion of In-Reactor Corrosion}

\section{Oxide Morphology and Thickness}

The morphology and thicknesses of oxide layers on Zircaloy from fuel and absorber rods irradiated in five reactors are shown in Fig. 8 and summarized in Table 1. Fuel rods from BWR-A and $-\mathrm{C}$ showed nodular oxides with maximum local thicknesses of up to $45 \mu \mathrm{m}$ after a burnup of 11-14 $\mathrm{MWd} / \mathrm{kgU}$. Other fuel rods and the absorber rods showed uniform waterside corrosion layers. The uniform oxide layer on Zircaloy-2 from BWR-B ras somewhat thicker, i.e., 50-70 $\mu \mathrm{m}$, after a burnup of 30 $\mathrm{MWd} / \mathrm{kgL}$. Compared to the normal operating temperature of $288^{\circ} \mathrm{C}$ of the other BWRs, the coolant outlet temperature of BWR-B was $307^{\circ} \mathrm{C}$. Higher cladding temperature, which is associated with the higher coolant temperature, is believed to be significant in the higher oxidation of the BWR-B fuel rods. The waterside oxidation of gadolinia rods from BWR-D 
was minimal (oxide layer 5-9 $\mu \mathrm{m}$ thick after a burnup of $24 \mathrm{MWd} / \mathrm{kgU}$ ); this is indicative of the relatively low operating temperature compared to that of the $\mathrm{UO}_{2}$ rods. However, the thickness of the corrosion layer on the inner surface of the gadolinia rod cladding was significantly greater than that of the $\mathrm{UO}_{2}$ rods.

\section{Intermetallic Precipitates}

Only two types of intermetallic precipitates containing $\mathrm{Fe}-\mathrm{Cr}$ or $\mathrm{Fe}-\mathrm{Ni}$ were identified, i.e., $\mathrm{Zr}(\mathrm{Fe}, \mathrm{Zr})_{2}$ and $\mathrm{Zr}_{2}(\mathrm{Fe}, \mathrm{Ni})$. Examples of TEM morphology and indexed selected-area diffraction (SAD) patterns of the hexagonal $\mathrm{Zr}(\mathrm{Fe}, \mathrm{Cr})_{2}$ (lattice constant $a=0.504 \mathrm{~nm}, c=0.816 \mathrm{~nm}$ ), and tetragonal $\mathrm{Zr}_{2}(\mathrm{Fe}, \mathrm{Ni})(\mathrm{a}=0.651 \mathrm{~nm}, \mathrm{c}=0.541 \mathrm{~nm})$ are shown in Fig. 9. After a neutron fluence of $3.3 \times 10^{21} \mathrm{n} \mathrm{cm}^{-2}(\mathrm{E}>0.1 \mathrm{MeV})$, the $\mathrm{Zr}(\mathrm{Fe}, \mathrm{Cr})_{2}$ precipitates contained in Zircaloy-2 BWR claddings were partially amorphized at their peripheries. The peripheral amorphization and dissolution of $\mathrm{Fe}, \mathrm{Cr}$, and $\mathrm{Ni}$ could be detected readily by comparing brightand dark-field images. No cubic modification of $\mathrm{Zr}(\mathrm{Fe}, \mathrm{Cr})_{2}$ precipitates was

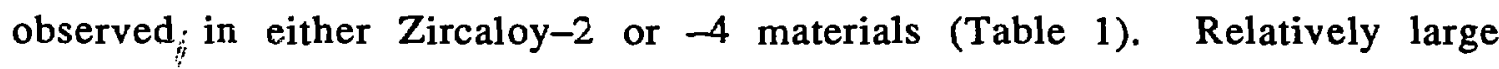
precipitates, on the order of several hundred nanometers, are also shown in Fig. 9 for other BWR fuel and gadolinia rods. The range of precipitate size for the BWR cladding is summarized in Table 1.

In the PWR-A cladding (fluence $4.4 \times 10^{21} \mathrm{n} \mathrm{cm}^{-2}$ ), it was difficult to find $\mathrm{Zr}(\mathrm{Fe}, \mathrm{Cr})_{2}$ precipitates that were still in crystalline form. It appeared that only a few oversize $\mathrm{Zr}(\mathrm{Fe}, \mathrm{Cr})_{2}$ precipitates (40-60 $\mathrm{nm}$ in size) survived irradiation-induced amorphization, and most of the smaller ones were fully amorphized and dissolved in the matrix. Typically, small holes (Fig. 10A) 
were observed in the electron-transparent region of the TEM specimens of PWR-A. Apparently, the holes were produced because of preferential localized corrosion attack during jet-thinning of the TEM specimen near the amorphi'red and dissolved $\mathrm{Zr}(\mathrm{Fe}, \mathrm{Cr})_{2}$ precipitates. Such holes were usually surrounded by amorphous regions that were 5-20 times larger than the precipitates (Figs. $10 \mathrm{~B}$ and 10C). It appears that irradiation-induced amorphization and dissolution are more extensive in PWR than in BWR cladding for a similar level of fluence; this probably reflects the effects of higher neutron flux or temperature of the PWR fuel rods, or both. In limited local regions, amorphization and dissolution appeared to be complete, resulting in local supersaturation of $\mathrm{Fe}$ and $\mathrm{Cr}$. In those regions, irradiation-induced spinodal-like fluctuation of solute atoms was manifested by alternating light and dark contrasts of several-hundrednanometer wavelength, as shown in the bright-field image in Fig. 11.

Correlation of Oxidation Pattern, Microstructure, and Temperature

As fluence increases, $\mathrm{Zr}(\mathrm{Fe}, \mathrm{Cr})_{2}$ precipitates in general undergo microstructural evolution, i.e., amorphization, dissolution, and in an extreme case, irrariation-induced spinodal-like fluctuation of the dissolved alloying elements. Precipitates of $\mathrm{Zr}(\mathrm{Fe}, \mathrm{Cr})_{2}$ seem to be more readily amorphized than those of $\mathrm{Zr}_{2}(\mathrm{Fe}, \mathrm{Ni})$ under similar irradiation conditions. Clear evidence of secondary precipitation of other metallic phases was not observed, except for localized spherical regions of light contrast (on the order of several hundred nanometers) and "white dots" (on the order of $<10 \mathrm{~nm}$ ) that seemed to be rich in metallic solute atoms. Distinct diffraction spots (e.g., those expected for Fe- or Sn-rich secondary phases) were not observed in these regions. 


\section{7}

The occurrence of nodular oxides in BWRs could best be correlated with the average size of intermetallic precipitates (i.e., their size before amorphization and dissolution), except for those of BWR-B. It seems evident that the larger the average size, the larger the susceptibility to nodular oxide formation. This observation is consistent with results of autoclave tests. Although it was difficult to quantify true corrosion rates because of variations in service temperature, burnup, and operating histories, oxidation was greater for BWR cladding with larger intermetallic precipitates.

In the case of BWR-B, a thick $(50-70 \mu \mathrm{m})$ uniform oxide layer, rather than nodular oxide, formed despite the large size of the intermetallic precipitates. This is attributed to a higher cladding temperature that is associated with the higher coolant-outlet temperature (i.e., 307 vs $288^{\circ} \mathrm{C}$ ). That is, for similar BWR water chemistries, nodular oxide formation appears to be strongly dependent on both intermetallic precipitate size and operating temperature. Regions of uniform and nodular oxide formation are illustrated schematically in Fig. 12 as a function of cladding temperature and average intermetallic precipitate size. A similar but temperature-independent boundary for uniform and nodular corrosion has been proposed by Garzarolli et al. in terms of accumulated annealing parameter. ${ }^{7}$ A previous study also discussed the strong effect of heat flux on nodular corrosion.44 However, in the present study, it was not possible to discern the heat-flux effect.

Irradiation-Induced Microstructures and Corrosion Acceleration 
The Zircaloy-2 fuel cladding of BWR-B, which operated at a relatively high temperature of $307^{\circ} \mathrm{C}$, exhibited other microstructural changes that are irradiation-induced. In this cladding, precipitation of $\mathrm{Zr}_{3} \mathrm{O}$ phase 45 was significant. Examples of TEM images of the $\mathrm{Zr}_{3} \mathrm{O}$ phase observed in the asirradiated cladding of the BWR-B are shown in Fig. 13. Because the $\mathrm{Zr}_{3} \mathrm{O}$ phase (produced by ordering of oxygen in the hcp structure of $\alpha \mathrm{Zr}$ ) is isostructural with $\alpha \mathrm{Zr}$, the true morphology of the phase can be obtained only from dark-field imaging by using its characteristic superlattice reflections. 45 Such dark-field images (shown in Fig. 13) are similar to those produced from $\alpha$-phase reflections of cold-worked and stressrelieved cladding. This indicates that the phase corresponds to bulk local regions in which ordering of oxygen solute occurred in the Zircaloy-2 cladding of BWR-B. The bulk nature of the phase is also corroborated by the orientation revealed in the SAD pattern of Fig. 13 and by the fact that it was observed only in irradiated materials, in particular the BWR-B cladding.

Besides the $\mathrm{Zr}_{3} \mathrm{O}$ phase, other bulk phases were also detected from the irradiated materials of Table 1, i.e., microscopic hydrides and cubic- $\mathrm{ZrO}_{2}$ precipitates. A good illustration of the presence and bulk nature of these phases is shown in Fig. 14, which summarizes results of a TEM stereo analysis of a specimen obtained from the Zircaloy-2 cladding of the BWR-D gadolinia rods. In the analysis, bright- and dark-field stereomicrographs were obtained from a thin-foil region for tilt angles of $-3.1,0,5$, and $10^{\circ}$. An example of bright-field images is shown in Fig. 14A, which was obtained for a tilt angle of $10^{\circ}$. Stereopairs of selected bright-field images, obtained for tilt angles 5 and $10^{\circ}$, are shown in reverse contrast in Figs. 
14B and 14C, respectively. Corresponding SAD patterns are shown in Figs. 14D and 14E, respectively. Analysis of the SAD patterns revealed reflections from $\delta$ hydrides and cubic $-\mathrm{ZrO}_{2}$ phases, in addition to those from surface-artifact hydrides. 45 The hydrides are visible in bright-field as dark features of nearly spherical or elliptical shape and $30-100 \mathrm{~nm}$ in size, and exhibit "strawberry-like" appearance (Fig. 14A). The "strawberrylike" appearance is believed to be produced because of superposition of images of microvoids. 45 Also visible in Fig. 14A are nearly spherical features of light contrast within the grain and nearly continuous strips of light contrast at the grain boundary. These regions of light contrast could not be identified; however, the contrasi indicates that the regions are rich in elements lighter than $\mathrm{Zr}$ atoms (e.g., $\mathrm{Fe}, \mathrm{Cr}$, and $\mathrm{Ni}$ ). Similar regions of light contrast have also been reported previously for Zircaloy-4 specimens irradiated to a fluence of 5 to $7 \times 10^{21} \mathrm{n} \mathrm{cm}^{-2}(\mathrm{E}>1 \mathrm{MeV})$ at 381 to $445^{\circ} \mathrm{C}^{46}$

The hydrides shown in Figs. 14A-14C are not the same as the long $\delta$ hydride stringers ( $50 \mathrm{~nm}$ wide and $\sim 1000 \mathrm{~nm}$ long) that can readily be resolved metallographically in most of the irradiated $\mathrm{Zr}$ alloys, e.g., those visible in Fig. 8. To resolve the nature of the smaller hydrides of Fig. 14 (i.e., bulk or surface nature), a stereoview examination of the bright-field image has been conducted. In Figs. 14B and C, 32 stereopair images were selected. The selected stereopair images were identified individually in Fig. 14F. Results of relative depth measurement of the 32 images, examined with a Cartographic Engineering Ltd. mirror stereoscope, are given in Fig. 14G. The relative depth of the images was determined from parallax (measured for each stereopair image with a stereoscope), tilt angle, and image magnification. 45 The result of Fig. $14 \mathrm{G}$ shows that the 
dark hydride lumps are distributed in the bulk of the film that is approximately $155 \mathrm{~nm}$ thick. A similar stereo analysis using micrographs of tilt angles 0 and $10^{\circ}$ revealed a film thickness of approximately $145 \mathrm{~nm}$.

Evidence for the bulk nature of the cubic- $\mathrm{ZrO}_{2}$ particles cannot be obtained from the bright-field stereopairs because the fine particles $\quad<10$ $\mathrm{nm}$ ) cannot be discerned from irradiation-induced "black-dot" defects in bright field. Therefore, extensive tilt experiments were conducted to obtain dark-field stereopairs of good quality. Care was taken to ensure accurate focusing of the dark-field images to minimize uncertainties due to the "two-and-a-half dimension" effect.47 The dark-field stereopairs of Figs. $14 \mathrm{H}$ and $14 \mathrm{I}$ were obtained for tilt angles -3.1 and $5^{\circ}$, respectively, from the $(\overline{1} 1 \overline{1})$ reflections of the cubic- $\mathrm{ZrO}_{2}$ phase (e.g., see Fig.14D).

Matching stereopairs of 24 images were identified and selected. These are denoted with small circles in Figs. $14 \mathrm{H}$ and 14I. In identifying the matching particles in the stereopair, great care was exercised because not all of the particles are visible in both micrographs. The diffraction conditions are not identical in the two micrographs of Figs. 14H and $14 \mathrm{I}$. Relative depth of the selected images, enhanced in intensity in Fig. 14J and identified individually in Fig. 14K, was determined from parallax measurement. The result, plotted in Fig. 14L, shows a more or less random distribution of cubic- $\mathrm{ZrO}_{2}$ particles through the thin-film region that is $\sim 162$ $\mathrm{nm}$ thick. A similar dark-field stereo analysis for tilt angles of 0 and $10^{\circ}$ resulted in a film thickness of $-160 \mathrm{~nm}$. The four film thicknesses measured from the bright- (tilt-angle pairs 5, 10 and $0,10^{\circ}$ ) and darkfield (tilt-angle pairs $-3.1,5$ and $0,10^{\circ}$ ) stereopair images, i.e., 145 to 162 $\mathrm{nm}$, are in good agreement, indicating that the "two-and-a-half dimension" 
effect in the dark-field analysis was negligible. Therefore, results of the stereo analysis show that either all or majority of the cubic- $\mathrm{ZrO}_{2}$ particles (i.e., 24 particles in Fig. 14K) are bulk precipitates. The bulk nature of the cubic- $\mathrm{ZrO}_{2}$ precipitates in Fig. 14 is further corroborated by the thicknessdependence of number density and the "through-focusing" characteristics. By switching back and forth between dark- and bright-field imaging, an individual precipitate of the cubic- $\mathrm{ZrO}_{2}$ phase can be singled out in bright field. For a surface particle, a change from over- to under-focusing in bright-field produces a corresponding white-to-black contrast change. 45 However, for a cubic- $\mathrm{ZrO}_{2}$ particle, bright-field contrast remained unchanged on switching from over- to under-focusing.

The small hydrides and cubic- $\mathrm{ZrO}_{2}$ precipitates, similar to those of Fig. 14, were also observed in the fuel ciadding of BWR-B and PWR-A, although their densities were somewhat lower. In a recent study, 31 cubic- $\mathrm{ZrO}_{2}$ precipitates were observed in all the irradiated specimens examined (fluence 5 to $17 \times 10^{21} \mathrm{n} \mathrm{cm}^{-2}$ ) but not in a specimen irradiated and subsequently annealed at $550^{\circ} \mathrm{C}$ for $48 \mathrm{~h}$.

It appears that local variation in the number density of the bulk microscopic hydrides and cubic- $\mathrm{ZrO}_{2}$ precipitates is significant even in the same cladding section. In particular, the density of the cubic- $\mathrm{ZrO}_{2}$ precipitates appeared to be associated with high fluence and high dissolved-oxygen content in the irradiated cladding. Reduced ductility and, in some cases, even brittle-type fracture were reported previously in association with high-density cubic- $\mathrm{ZrO}_{2}$ precipitates and hydrides. 47 The effect of irradiation-induced precipitation of the cubic- $\mathrm{ZrO}_{2}$ or $\mathrm{Zr}_{3} \mathrm{O}$ phases on ductility reduction appears to be consistent with the observation of $\mathrm{Oi}$ 
et al.16 in which irradiation-induced hardness increase was more pronounced for materials containing more oxygen (i.e., an increase of 90 Vickers hardness for Zircaloy-2 vs. 30 for crystal-bar $\mathrm{Zr}$ ). In general, accumulation of macroscopic and microscopic hydrides, irradiation-induced oxide, and suboxide is likely to occur in an extended-burnup fuel cladding underneath a thick oxide layer, e.g., the oxide of Fig. 1 in Ref. 48. This will, in effect, embrittle the local metal at the metal-oxide boundary, and, as a result, facilitate cracking along the metal/oxide boundary under the stress that is generated by the oxide formation. That is, the repeated microcracking process 48 usually associated with porous accelerated oxide growth is likely to be more pronounced and continuous along the boundary.

Measurements of accelerated oxidation for PWR extended-burnup fuels show oxide thicknesses as high as $110 \mu \mathrm{m}$, well beyond the "thick-film" threshold 4 of $15-20 \mu \mathrm{m}$ beyond which changes in water chemistry within the porous cracked oxide are believed to accelerate oxidation. In the range of such large oxide thicknesses (e.g., $>70 \mu \mathrm{m}$ ), observations indicate that the oxidation at rod-average burnups higher than $45 \mathrm{MWd} / \mathrm{kg}$ was larger than that extrapolated from the lower-burnup data of $<40 \mathrm{MWd} / \mathrm{kg} .49-53$ Thus, another type of oxidation acceleration is indicated for extended burnup of $>45 \mathrm{MWd} / \mathrm{kg}$. The irradiation enhancement factor for in-reactor oxidation also appears to increase at burnups of $>45 \mathrm{MWd} / \mathrm{kg}$. Thick oxide layers produced in extended-burnup fuel rods frequently show long cracks near the metal-oxide boundary that are continuous and parallel to the boundary, indicating a more pronounced separation along the boundary during the extended-burnup service. Frequently, evidence suggests that 
intercrack spacing decreäses (i.e., accelerated microcracking) as the fluence increases, e.g., Ref. 48. It is difficult to explain this phenomenon on the basis of the effect of increasing temperature of the oxide/metal boundary alone, because under otherwise identical conditions, a higher boundary temperature will result in a larger intercrack spacing. It is also difficult to explain on the basis that water chemistry in the oxide cracks becomes increasingly more aggressive during extended burnup. Instead, it is suggested that the more pronounced microcracking may be associated with increasing embrittlement of metal near the metal-oxide boundary as a result of the increased precipitation of hydrides and small cubic- $\mathrm{ZrO}_{2}$ particles, the latter apparently formed via an irradiation-induced process. This effect, combined with a higher metal/boundary temperature, may be an important factor in accelerated corrosion for extended-burnup service.

\section{Conclusions}

1. Nodular corrosion characteristics of recrystallized Zircaloy-4 from static autoclave tests at $500^{\circ} \mathrm{C}$ and $10.3 \mathrm{MPa}$ were investigated. A good correlation was obtained between the average size of intermetallic precipitates and weight gain. Exceptions were noticed in a similar correlation with nodule coverage and nodule number density. These results could be best explained on the basis of the hypothesis that nodules nucleate in local regions that are depleted of $\mathrm{Fe}$ and $\mathrm{Cr}$ alloying elements. Some of the observations were inconsistent with the premise that nodules nucleate on or near the intermetallic precipitates.

2. Nodular corrosion characteristics and microstructures of commercial Zircaloy-2 cladding of fuel and gadolinia rods, obtained from several BWRs 
after burnup of 11-30 $\mathrm{MWd} / \mathrm{kgU}$, have been examined. Partial amorphization of the $\mathrm{Zr}(\mathrm{Fe}, \mathrm{Cr})_{2}$ precipitates in BWR Zircaloy-2, and virtual dissolution and, in extreme case, spinodal-like fluctuation of dissolved alloying elements in PWR Zircaloy-4 cladding were observed. Occurrence of nodular oxidation in BWRs could best be correlated with average size of the intermetallic precipitates before irradiation and with fuel cladding temperature. For a similar intermetallic size range of $250-700 \mathrm{~nm}$, nodular oxides were observed for a normal BWR temperature of $288^{\circ} \mathrm{C}$, but only thick uniform oxide was observed for operation at $307^{\circ} \mathrm{C}$.

3. For extended-burnup operation, increased precipitation of hydrides, suboxides, and small oxide particles occurs, apparently via an irradiationinduced process. This is likely to result in more pronounced microcracking along the metal/oxide boundary. In addition to a higher metal/oxide boundary temperature, the more pronounced microcracking may be associated with the corrosion acceleration reported for extended-burnup service of $>45 \mathrm{MWd} / \mathrm{kgU}$.

\section{Acknowledgments}

This study has been conducted as a joint work by the Korea Atomic Energy Research Institute, the Republic of Korea, and Argonne National Laboratory, U.S.A. The authors are grateful for the experimental contributions provided by R. A. Conner, Jr., D. Donahue, and A. Philippides for preparation of SEM sand TEM specimens of the irradiated fuel cladding. 


\section{References}

1. Perkins, R. A., Busch, R. A., and Bradley, E. R., "Effect of Oxide Structure on Nodular Corrosion Susceptibility," Proc. of the IAEA Technical Committee Meeting on Fundamenral Aspects of Corrosion of Zirconium-Base Alloys for Water Reactor Environments, Sept. 11-15, 1989, Portland, OR, IWGFFT/34, International Atomic Energy Agency, Vienna, 1990, pp. 120-123.

2. Andersson, T., and Thorvaldsson, T., "Influence of Microstructure on 500 and $400^{\circ} \mathrm{C}$ Steam Corrosion Behavior of Zircaloy--2 and Zircaloy-4 Tubing," ibid., pp. 237-248.

3. Taylor, D. F., Cheng, B., and Adamson, R. B., "Nodular Corrosion Mechanisms and Their Application to Alloy Development," ibid., pp. 27-35.

4. Johnson, Jr., A. B., "Thick-Film Effects in the Oxidation and Hydriding of Zirconium Alloys," ibid., pp. 107-120.

5. Ramasubrananian, N., "Nodule Nucleation At and Away from Intermetallics," ibid., pp. 36-44.

6. Graham, R. A. Tosdale, J. P., and Finden, P. T., "Influence of Chemical Composition and Manufacturing Variables on Autoclave Corrosion of the Zircaloys," Zirconium in the Nuclear Industry: Eighth International Syrnposium, ASTM STP 1023, L. F. P. Van Swam and C. M. Eucken, eds., American Society for Testing and Materials, Philadelphia, 1989, 334-345.

7. Garzarolli, F., Steinberg, E., and Weidinger, H. G., "Microstructure and Corrosion Studies for Optimized PWR and BWR Zircaloy Cladding," ibid., 202-212.

8. Rudling, P., Pettersson, H., Andersson, T., and Thorvaldsson, T., "Corrosion Performance of Zircaloy-2 and Zircaloy-4 PWR Fuel Cladding," ibid., 213-226.

9. Ogata, K., et al., "A Systematic Survey of the Factors Affecting Zircaloy Nodular Corrosion," ibid., 291-314.

10. Rudling, P., and Machiels, A. J., "Corrosion Performance Ranking of Zircaloy-2 for BWR Applications," ibid., 315-333. 
11. Ogata, K., "Effects of Alloying Element Distribution on the Nodular Corrosion of Zircaloy-2," ibid., 346-359.

12. Zhou, B.-X., "Electron Microscopy Study of Oxide Films Formed on Zircaloy-2 in Superheated Steam," ibid., 360-373.

13. Charquet, D., Tricot, R., and Wadier, J.-F., "Heterogeneous Scale Growth During Steam Corrosion of Zircaloy -4 at $500^{\circ} \mathrm{C}$," ibid., $374-391$.

14. Thorvaldsson, T., Andersson, T., Wilson, A., and Wardle, A. M., "Correlation between $400^{\circ} \mathrm{C}$ Steam Corrosion Behavior, Heat Treatment, and Microstructure of Zircaloy-4 Tubing," ibid., 128-140.

15. Sofer, G. A., Hansen, L. E., Van Swam, L. F. P., and Patterson, J. F., "Performance of Advanced Nuclear Fuels Corporation Fuel in Light Water Reactors," in Proc. Intl. Topical Mtg. on LWR Fuel Performance, Williamsburg, VA, April 17-20, 1988, pp. 41-53.

16. Oi, N., Maki, H., Kawada, T., Yamanouchi, A., and Nomura, M., "BWR Fuel Performance and Recent Trend of R\&D in Japan," ibid., 21-30.

17. Garzarolli, F., and Stehle, H., "Behavior of Core Structural Materials in Light Water Cooled Power Reactors," in Proc. IAEA Symp. "Improvements in Water Reactor Fuel Technology and Utilization," Stockholm, Sweden, Sept. 15-19, 1986, International Atomic Energy Agency, Vienna, 1987, pp. 387-407.

18. Rudling, P., Vannesjo, K. L., Vesterlund, G., and Massih, A. R., "Influence of Second-phase Particles on Zircaloy Corrosion in BWR Environment," Zirconium in the Nuclear Industry: Seventh International Symposium, ASTM STP 939, R. B. Adamson and L. F. P. Van Swam, eds., American Society for Testing and Materials, Philadelphia, 1987, 292-306.

19. Maussner, G., Steinberg, E., and Tenckhoff, E., "Nucleation and Growth of Intermetallic Precipitates in Zircaloy-2 and Zircaloy-4 and Correlation to Nodular Corrosion Behavior," ibid., 307-320.

20. Andersson, T., and Thorvaldsson, T., "Nodular Corrosion Resistance of Zircaloy-2 in Relation to Second-phase Particle Distribution," ibid., 321-337.

21. Bangaru, N. V., Busch, R. A., and Schemel, J. H., "Effect of Beta Quenching on the Microstructure and Corrosion of Zircaloys," ibid., 341-363. 
22. Garzarolli, F., Stehle, H., Steinberg, E., and Weidinger, H., "Progress inı the Knowledge of Nodular Corrosion," ibid., 417-430.

23. Charquet, D., Steinberg, E., and Millet, Y., "Influence of Variations in Early Fabrication Steps on Corrosion, Mechanical Properties, and Structure of Zircaloy-4 Products," ibid., 431-447.

24. Weidinger, H. G., Garzarolli, F., Eucken, C. M., and Baroch, E. F., "Effect of Chemistry on Elevated Temperature Nodular Corrosion," ibid., 364386.

25. Cheng, B., and Adamson, R. B., "Mechanistic Studies of Zircaloy Nodular Corrosion," ibid., 387-416.

26. Urbanic, У. F., Cox, B., and Field, G. J., "Long-term Corrosion and Deuterium Uptake in CANDU-PHW Pressure Tubes," ibid., 189-205.

27. Griffiths, M., Gilbert, R. W., and Cheadle, B. A., Proc. Workshop on Second Phase Particles in Zircaloys, Erlangen, West Germany, June 1985; also issued as AECL-8852.

28. Yang, W. J. S., Tucker, R. P., Cheng, B., and Adamson, R. B., J. Nucl. Mater. 138 (1986), 185-195.

29. Gilbert, R. W., Griffiths, M., and Carpenter, G. I. C., J. Nucl. Mater. 135 (1985), 265-268.

30. Harris, L. L., and Yang, W. J. S., "Radiation-induced Changes in Microstructure," 13th Intl. Symp. (Part I), ASTM STP 955, F. A. Garner, et al., ed., American Society for Testing and Materials, Philadelphia, 1987, pp. 661-675.

31. Garzarolli, F., Dewes, P., Maussner, G., and Basso, H.-H., "Effects of High Neutron Fluences on Microstructure and Growth of Zircaloy-4," Zirconium in the Nuclear Industry: Eighth International Symp., ASTM STP 1023, L. F. P. Van Swam and C. M. Eucken, eds., American Society for Testing and Materials, Philadelphia, 1989, pp. 641-657.

32. Yang, W. J. S. and Adamson, R. B., "Beta-Quenched Zircaloy-4: Effectsof Thermal Aging and Neutron Irradiation," ibid., 451-477.

33. Bentley, M. J., "Oüt of Reactor Studies of the Nodular Oxidation of Zirconium Alloys," UKAEA-TRG Report 3001(s), 1977. 
34. Oestberg, G., "Metallographic Study of Isothermal Transformation of Beta Phase in Zircaloy-2," Jernkontorets Ann. 145 (1963) 119.

35. Charquet, D., et al., "Solubility Limits and Formation of Intermetallic Precipitates in ZrSnFeCr Alloys," Zirconium in the Nuclear Industry: Eighth Symposium, ASTM STP 1023, L. F. P. Van Swam and C. M. Eucken, Eds., American Society for Testing and Materials, Philadelphia, 1988, pp. 405-422.

36. Heinrich, K. F. J., "Microprobe Study of Zircaloy Corrosion Films," AEC Research and Development Report DP-906, Savannah River Laboratory, November 1964.

37. Chung, H. M., and Kassner, T. F., "Embrittlement Criteria for Zircaloy Fuel Cladding Applicable to Accident Situations in Light-Water Reactors: Summary Report," Argonne National Laboratory Report, ANL-79-48, January 1980.

38. Garde, A. M., Aigeltinger, E., Woodruff, B. N., and Reed-Hill, R. E., "Concerning the Strength of Dynamic Strain Aging in Zirconium," Met. Trans. 6A (1975), 1183.

39. Veevers, K., "Strain Aging in Zirconium Alloys," J. Nucl. Mater. 55, (1975), 109.

40. Kelly, P. M., and Smith, P. D., "Strain Aging in Zirconium-Oxygen Alloys," J. Nucl. Mater. 46 (1973), 23.

41. Veevers, K., and Rotsey, W. B., "Effect of Irradiation on Strain Aging in Annealed Zircaloy-2," J. Nucl. Mater. 27 (1968), 108.

42. Veevers, K., Rotsey, W. B., and Snowden, K. U., "The Effect of Neutron Irrediation and Cold Work on the Strain Aging Behavior of Zircaloy2," Application Related Phenomenon in Zirconium and Its Alloys, ASTM STP 458, American Society for Testing and Materials, 1969, pp. 194-209.

43. Garde, A. M., and Kassner, T. F.,"Uniaxial Tensile Properties of Zircaloy Containing Oxygen: Summary Report," Argonne National Laboratory Report, ANí-77-30, June 1977.

44. Franklin, D., and $\mathrm{Li}, \mathrm{C} .-\mathrm{Y}$. , in Zirconium in the Nuclear Industry: Seventh International Symposium, ASTM STP 939, B. B. Adamson and L. F. $\ddot{P}$. Van Swam, eds., American Society for Testing and Materials, Philadelphia, 1987, pp. 206-223. 
45. Chung, H. M., Radiation-induced Changes in Microstructure: 13th International Symposium (Part I), ASTM STP 955, F. E. Garner et al., ed., American Society for Testing and Materials, Philadelphia, 1987, pp. 676-699.

46. Adamson, R. B., Tucker, R. P., and Fidleris, V.; in Zirconium in the Nuclear Industry: 5th Conference, ASTM STP 754, D. G. Franklin, ed., American Society for Testing and Materials, Philadelphia, 1982, pp. 208-234.

47. Chung, H. M., Yaggee, F. L., and Kassner, T. F., in Zirconium in the Nuclear Industry: 7th International Symposium, ASTM STP 939, Adamson and Van Swam, eds., American Society for Testing and Materials, Philadelphia, 1987, pp. 775-801.

48. Stehli, H., Garzarolli, G., Garde, A. M., and Smerd, P. G., "Characterization of $\mathrm{ZrO}_{2}$ Films Formed In-Reactor and Ex-Reactor to Study the Factors Contributing to the In-Reactor Waterside Corrosion of Zircaloy," Zirconium in the Nuclear Industry: Sixth International Symposium, ASTM STP 824, D. G. Franklin and R. B. Adamson, eds., American Society for Testing and Materials, 1984, pp. 483-506.

49. Holzer, R., and Knaab, H., in Proc. ANS Topical Meeting on LWR Fuel Performance, April 17-20, 1988, Williamsburg, VA; American Nuclear Society, La Grange Park, IL, pp. 69-80.

50. Newman, L. W., Babcock and Wilcox, BAW-1874 (DOE/ET/34212-50), October 1986.

51. Andrews, M. G., Smith, G. P., and Shubert, M. A., in Proc. ANS Topical Meeting on LWR Fuel Performance, April 17-20, 1988, Williamsburg, VA; American Nuclear Society, La Grange Park, IL (1988), pp. 90-95.

52. Kaiser, R. S., Miller, R. S., Moon, J. E., and Pisano, N. A., in Proc. ANS Topical Meeting on LWR Fuel Performance, April 17-20, 1988, Williamsburg, VA; American Nuclear Society, La Grange Park, IL (1988), pp. 119-124.

53. Garzarolli, F., et al., "Review of PWR Fuel Rod Waterside Corrosion Behavior," EPRI NP-1472, Electric Power Research Institute, 1980. 
Table 1. Summary of BWR and PWR Fuel and Gadolinia Absorber Rods Examined for Characterization of Cladding Microstructure and Waterside Corrosion

\begin{tabular}{|c|c|c|c|c|c|c|c|}
\hline Reactor & Fuel & $\underset{\text { Burnup }}{\text { BWd/kgU) }}$ & $\begin{array}{l}\text { Cladding } \\
\text { State }\end{array}$ & $\begin{array}{c}\text { Fluence } \\
\left(10^{21} \mathrm{n} \mathrm{cm}^{-2},\right. \\
\mathrm{E}>0.1 \mathrm{MeV})\end{array}$ & $\begin{array}{c}\text { Oxide } \\
\text { Morphology }\end{array}$ & $\begin{array}{c}\text { Oxide Layer } \\
\text { Thickness } \\
(\mu \mathrm{m})\end{array}$ & $\begin{array}{c}\text { Size of } \\
\text { Intermetallic } \\
\text { Precipitates } \\
\text { (nm) }\end{array}$ \\
\hline BWR-A & $\mathrm{UO}_{2}$ & 14 & Annealed & 2.2 & Nodular & $3-45$ & $340-750$ \\
\hline BWR-B 1 & $\mathrm{UO}_{2}$ & 30 & $\begin{array}{l}\text { Cold-worked } \\
\text { Stress-relieved }\end{array}$ & 3.3 & $\begin{array}{c}\text { Uniform - } \\
\text { thick }\end{array}$ & $50-70$ & $300-600$ \\
\hline BWR-C & $\mathrm{UO}_{2}$ & 11 & Annealed & 1.6 & Nodular & $2-40$ & $320-730$ \\
\hline BWR-D2 & $\mathrm{UO}_{2}-3 \% \mathrm{Gd}_{2} \mathrm{O}_{3}$ & 24 & $\begin{array}{l}\text { Cold-worked } \\
\text { Stress-relieved }\end{array}$ & 3.1 & $\begin{array}{l}\text { Uniform - } \\
\text { thin }\end{array}$ & $5-9$ & $240-480$ \\
\hline PWR-A & $\mathrm{UO}_{2}$ & 28 & $\begin{array}{l}\text { Cold-worked } \\
\text { Stress-relieved }\end{array}$ & 4.4 & $\begin{array}{l}\text { Uniform - } \\
\text { cracked }\end{array}$ & $20-30$ & $40-100$ \\
\hline
\end{tabular}

${ }^{1}$ Coolant outlet temperature $307^{\circ} \mathrm{C}$ instead of normal BWR temperature of $288^{\circ} \mathrm{C}$.

${ }^{2}$ Operating temperature of the gadolina-containing absorber rod was $-240^{\circ} \mathrm{C}$. 

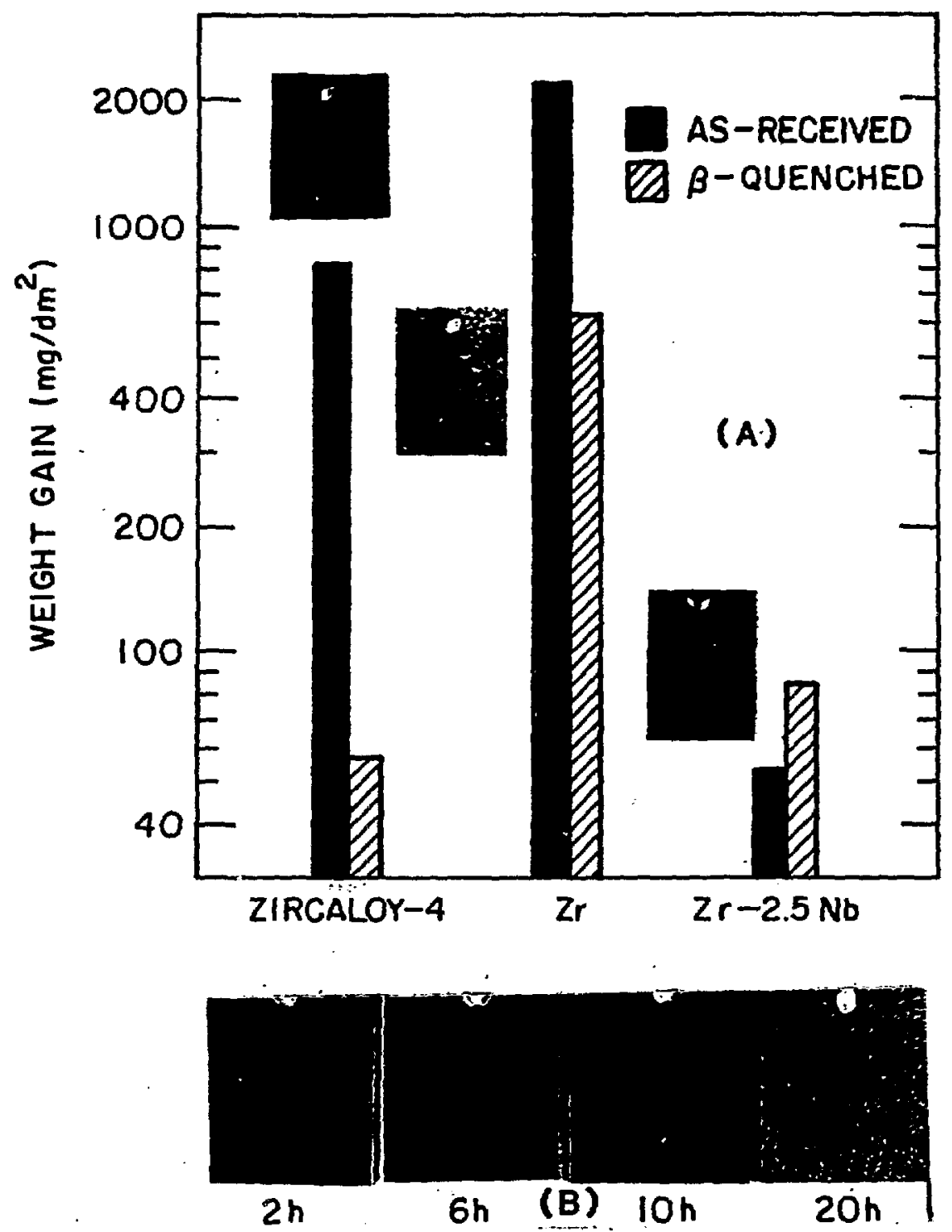

Fig. 1. Results of Scoping Nodular Corrosion Tests on Zircaloy-4, Zr, and $\mathrm{Zr}-2.5 \mathrm{Nb}$, Showing Relative Nodule Appearance and Weight Gain (A). Sequence of nodule development in Zircaloy-4 is shown in (B). 


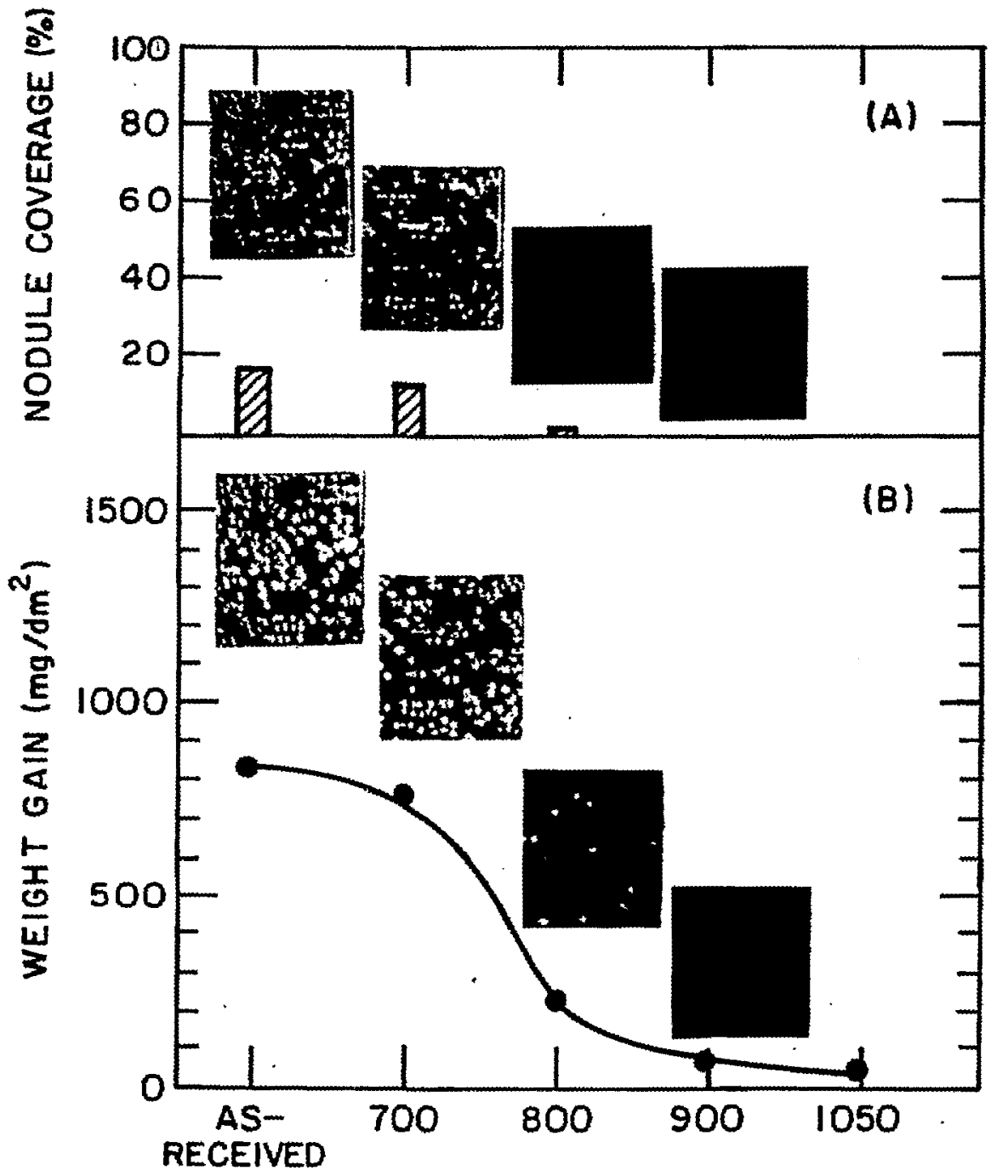

ANNEALING TEMPERATURE $\left({ }^{\circ} \mathrm{C}\right)$

Fig. 2. Effects of Annealing Temperature on Nodule Coverage (A) and Weight Gain (B) for Zircaloy-4. Nodule appearances after 24 and $48 \mathrm{~h}$ corrosion at $500^{\circ} \mathrm{C}$ are also shown in (A) and (B), respectively. 

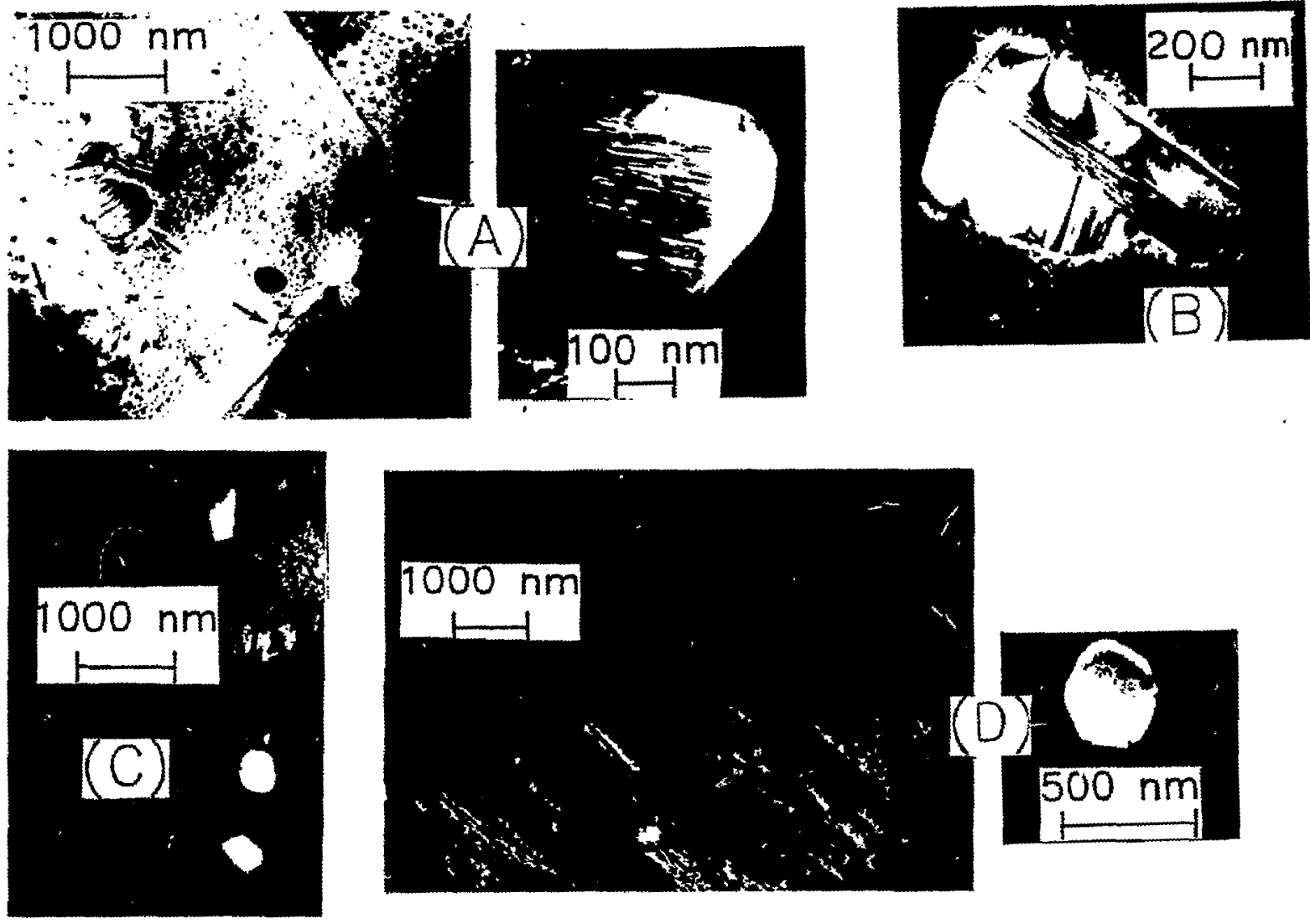

Fig. 3. Dark- and Bright-Field Morphologies Showing $\mathrm{Zr}_{2}(\mathrm{Fe}, \mathrm{Cr})$

Precipitates Observed by TEM after Various Annealing, Cooling, and Cold Work. (A) As-received; (B)-(D) water-quenched after anneal at 700,800 , and $900^{\circ} \mathrm{C}$, respectively; (E)-(G) dark-field images of transformed structure and precipitate after annealing at $1050^{\circ} \mathrm{C}$ and water-quench, air-cool, and furnace-cool; and $(\mathrm{H}) 30 \%$ cold-worked specimens. 

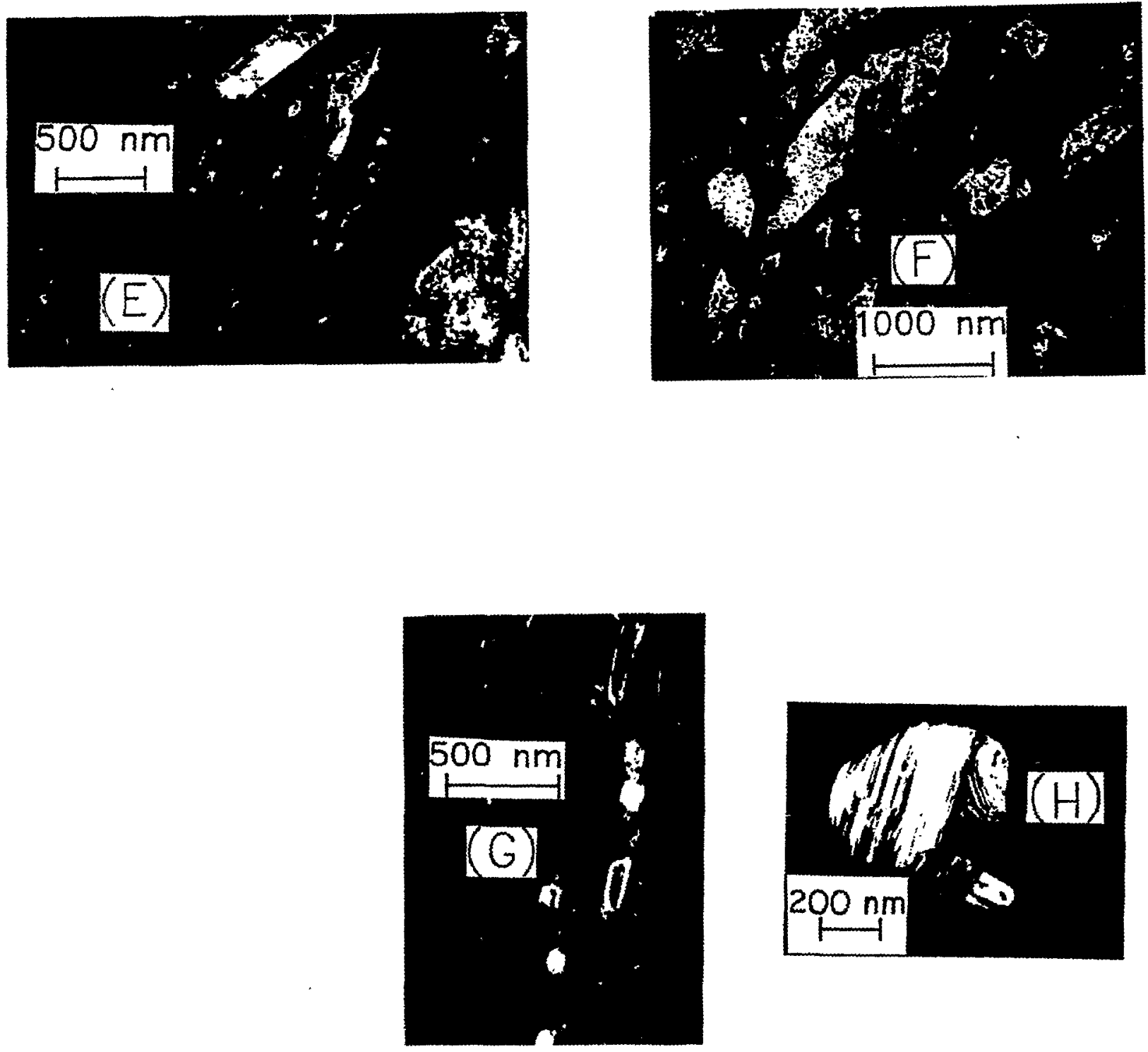

Fig. 3. Cont. 


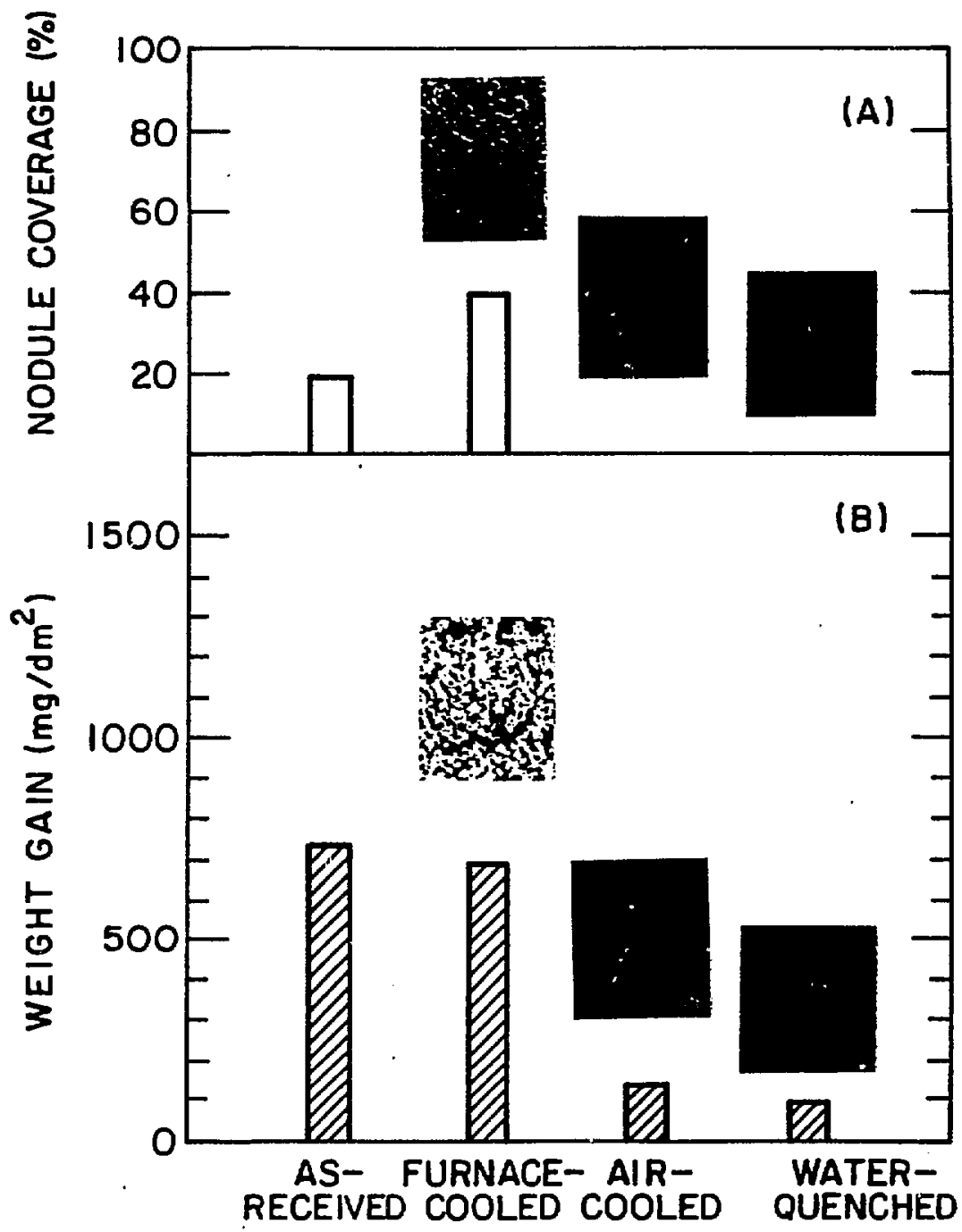

Fig. 4. Effects of Cooling Rate after $\beta$-Annealing at $1050^{\circ} \mathrm{C}$ on Nodule Coverage (A) and Weight Gain (B). Nodule appearances after 24and 48 -h corrosion at $500^{\circ} \mathrm{C}$ are also shown in (A) and (B), respectively. 


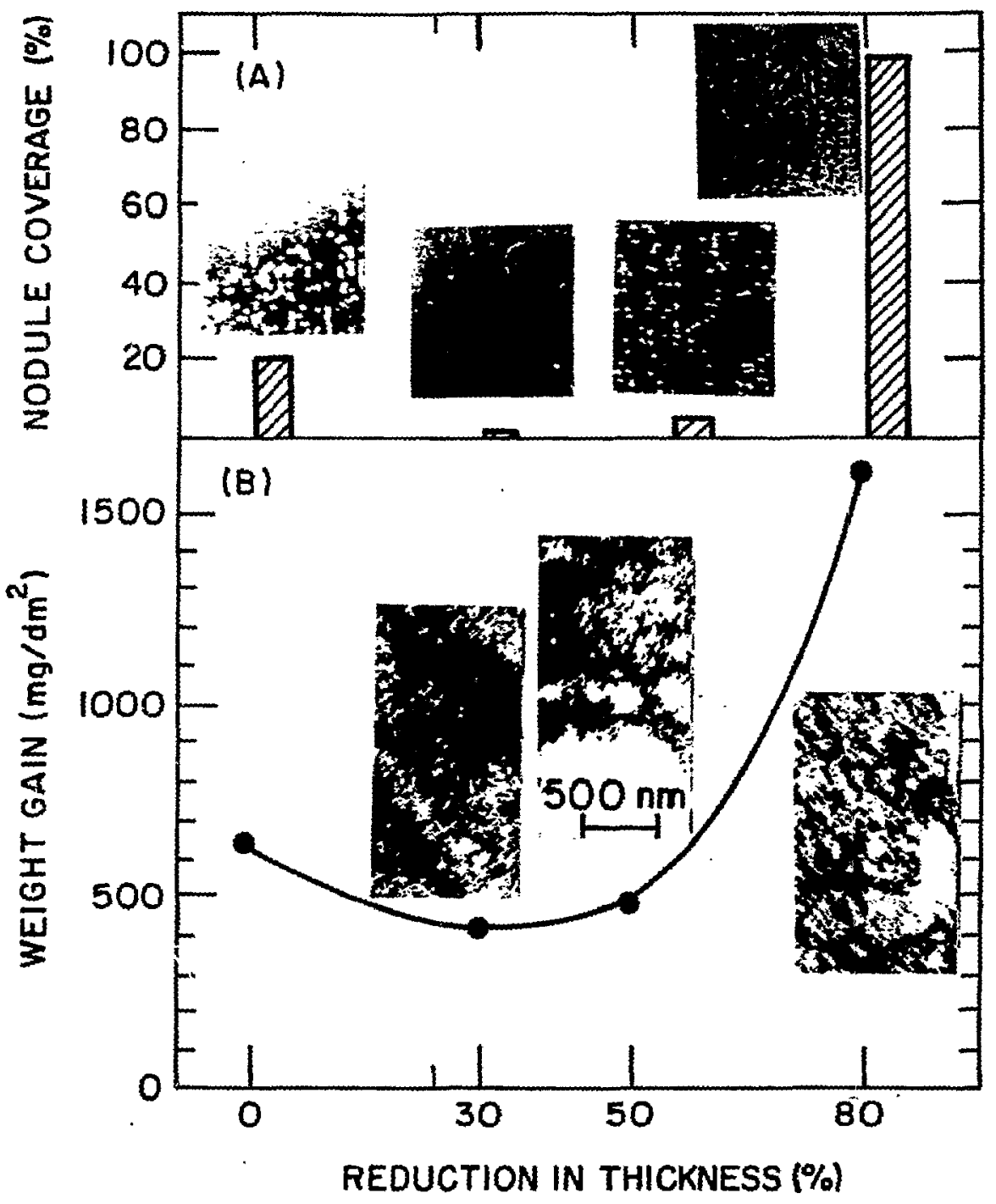

Fig. 5. Effect of Cold Work on Nodule Coverage (A) and Weight Gain (B) for Corrosion at $500^{\circ} \mathrm{C}$ for $24 \mathrm{~h}$. Nodule appearance and TEM images of cell structures are shown in (A) and (B), respectively. 


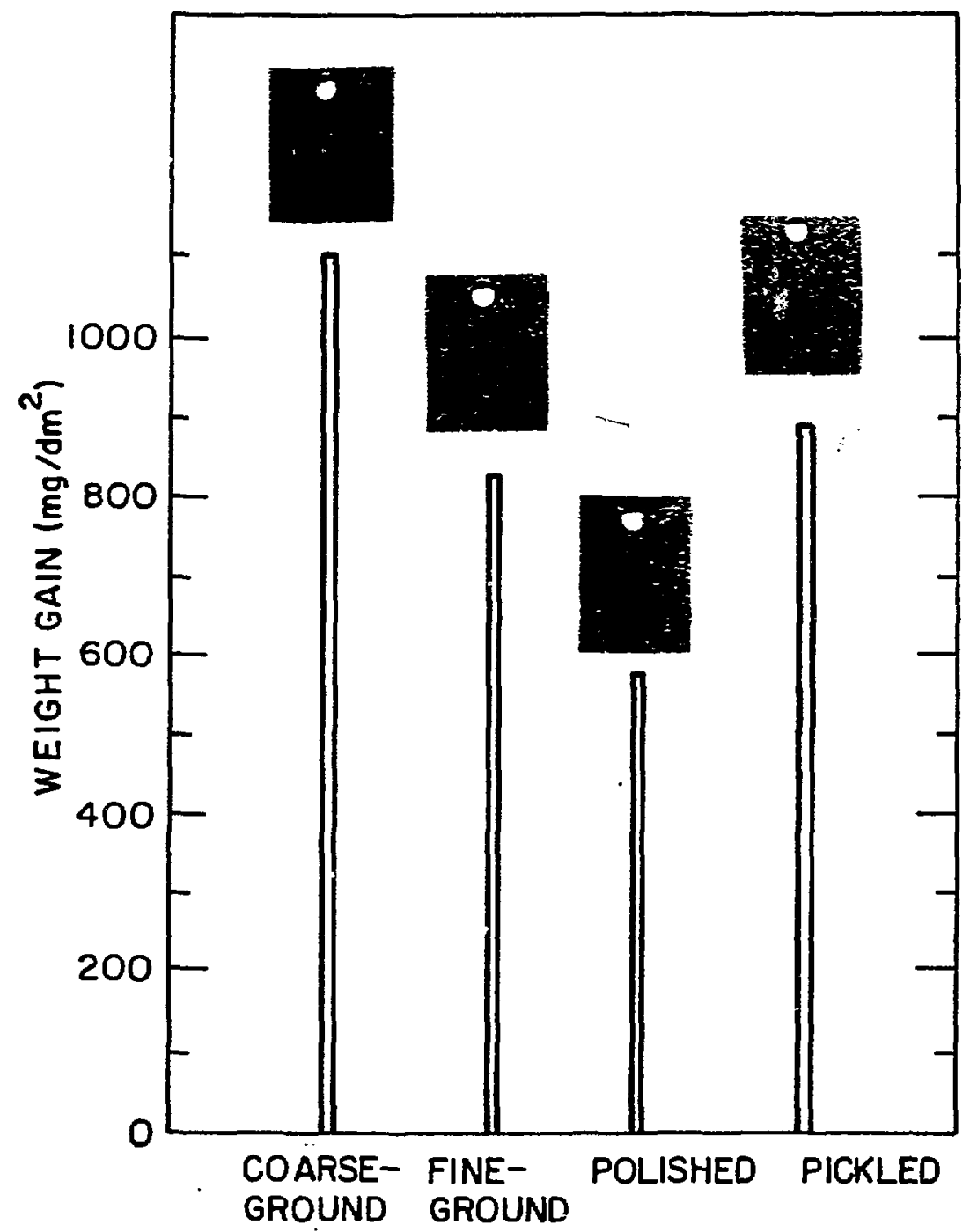

Fig. 6. Effect of Surface Treatment on Weight Gain and Nodule Appearance. 


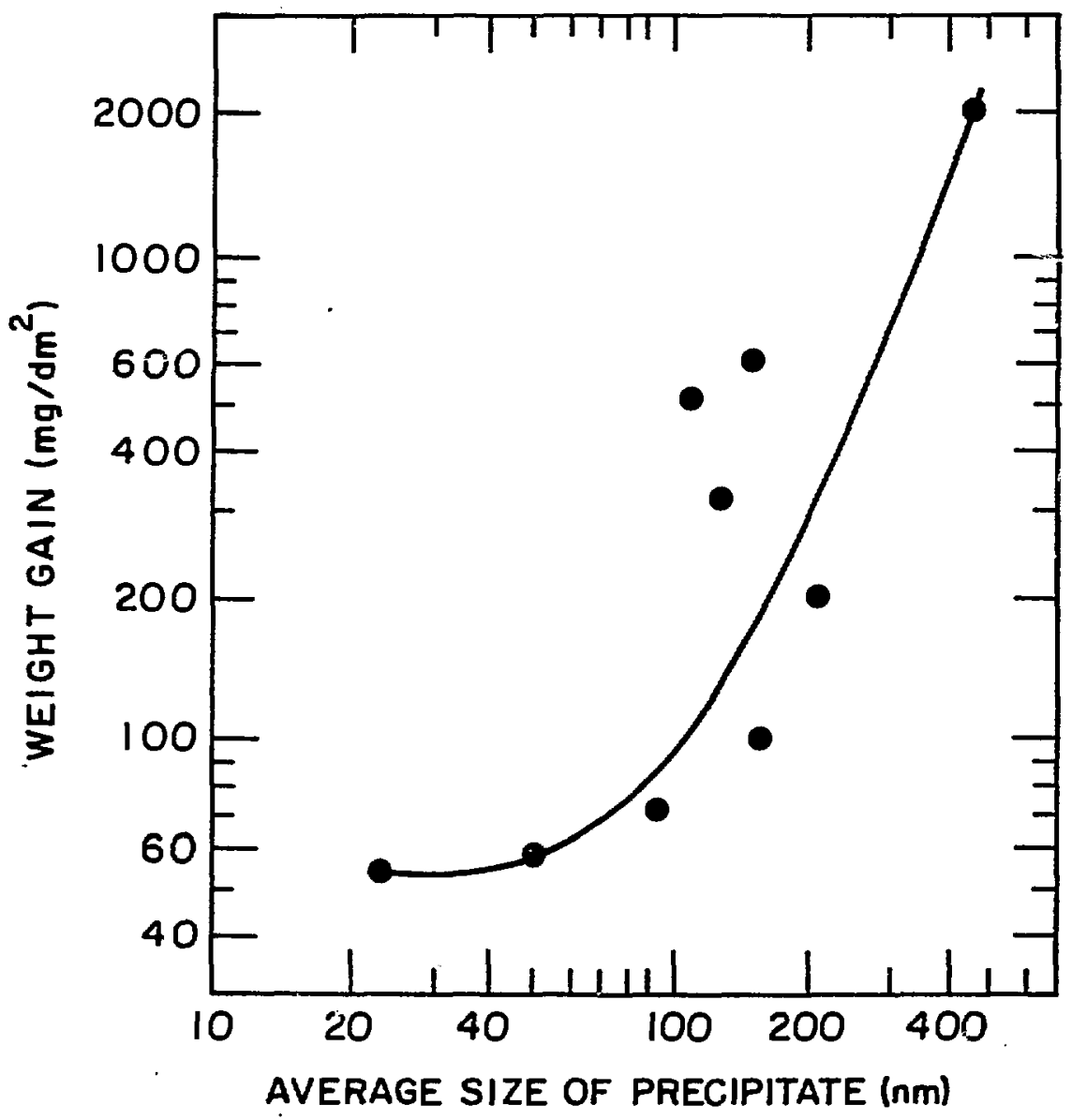

Fig. 7. Weight Gain after Corrosion ố Zircaloy-4 at $500^{\circ} \mathrm{C}$ for $48 \mathrm{~h}$ vs. Average Size of Intermetallic Precipitates. 

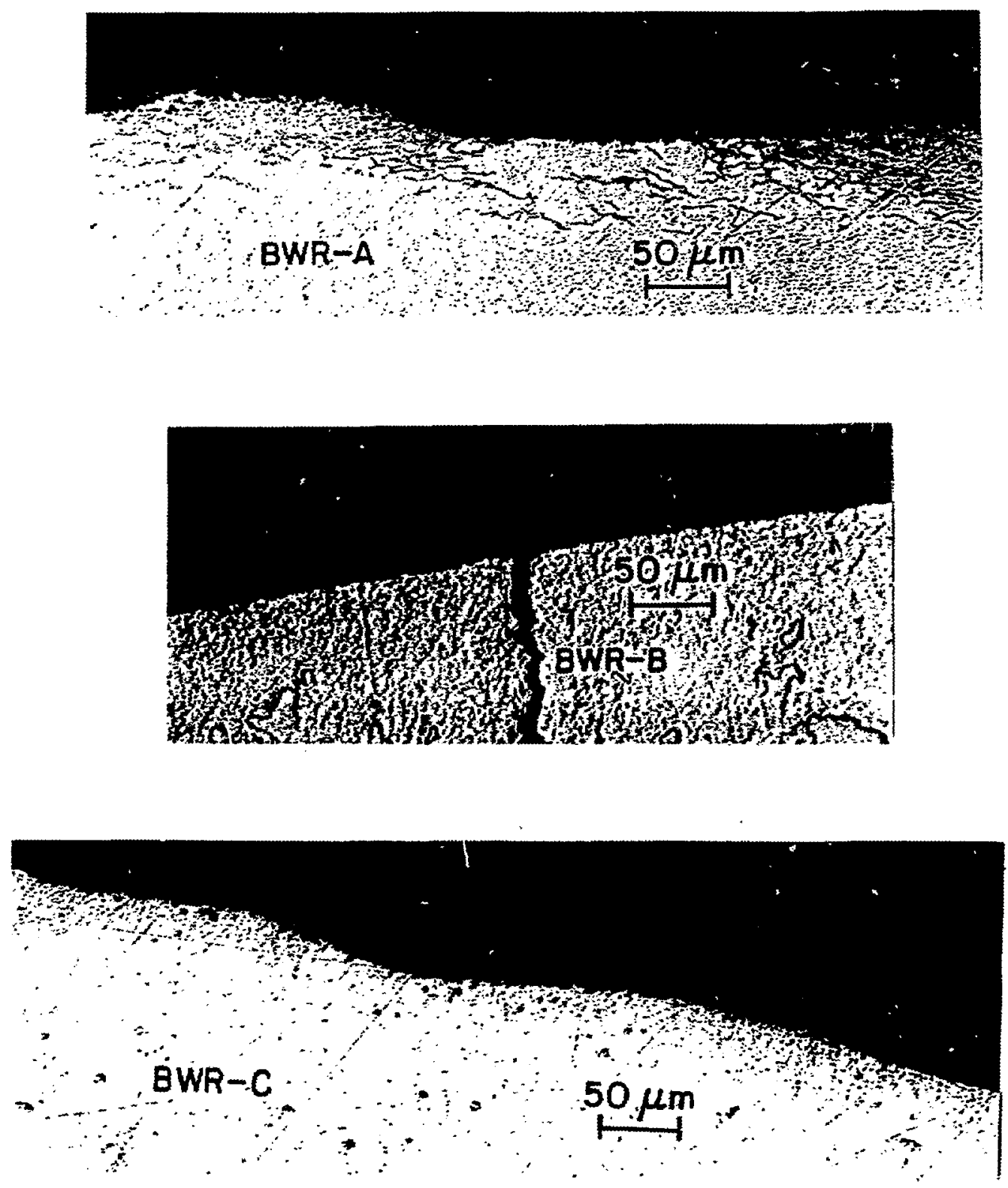

Fig. 8. Morphology and Thickness of Waterside Corrosion Layers of Fuel and Absorber Rods Obtained from BWR-A, $-B,-C$, and $-D$, and PWR-A. 

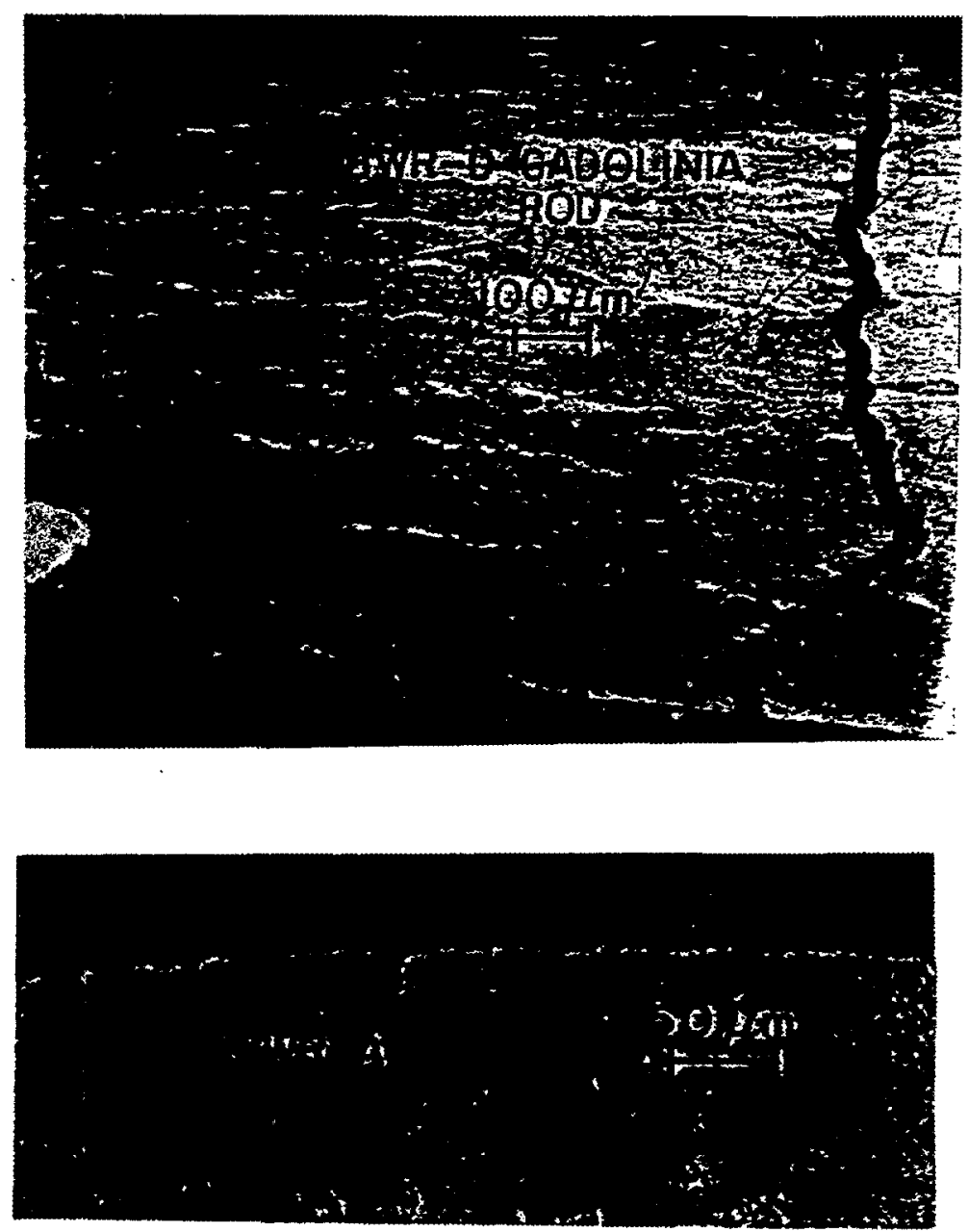

Fig. 8. Cont. 

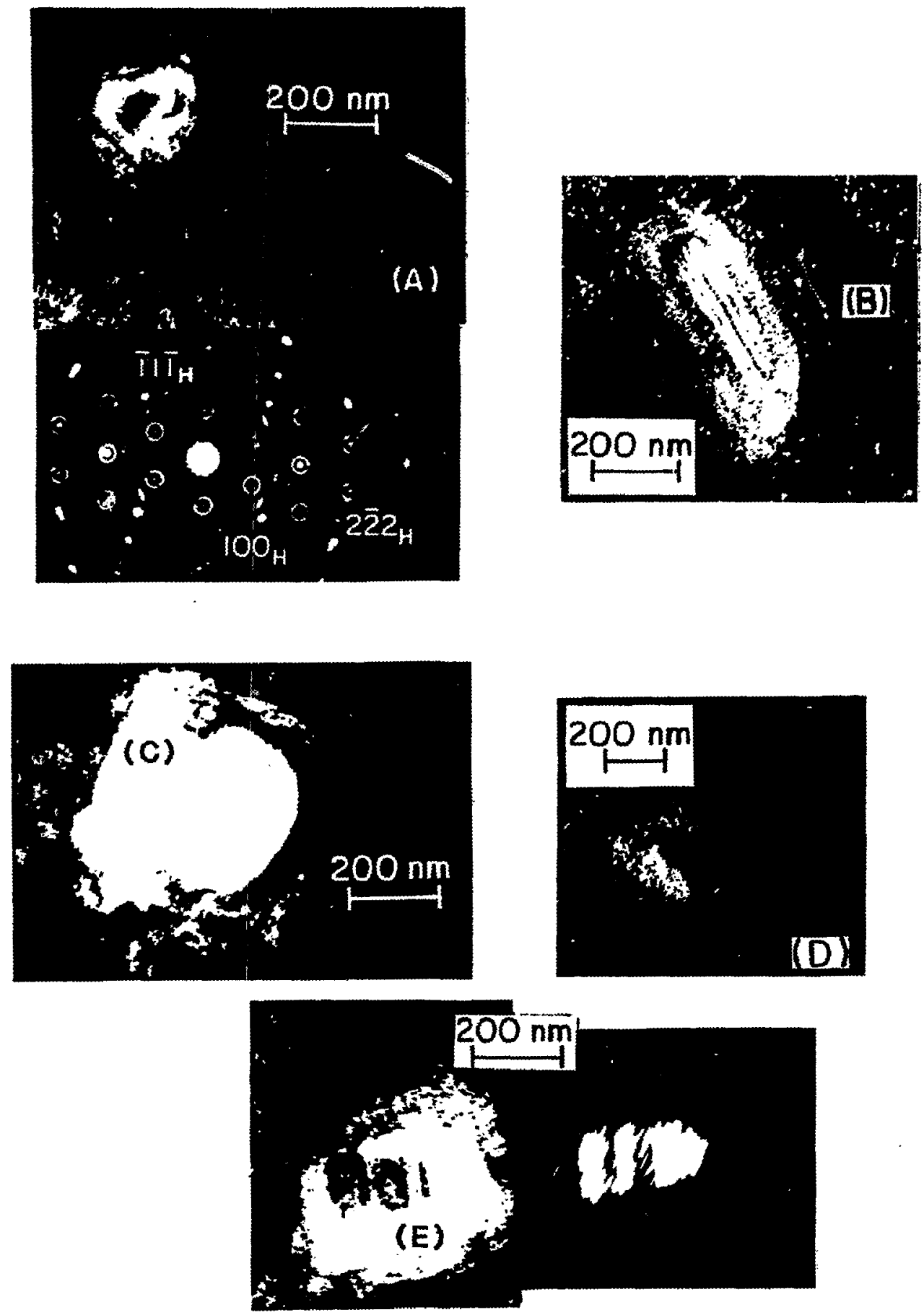

Fig. 9. Morphology and SAD Pattern of a $\mathrm{Zr}(\mathrm{Fe}, \mathrm{Cr})_{2}(\mathrm{~A})$, and a $\mathrm{Zr}_{2}(\mathrm{Fe}, \mathrm{Ni})$ Precipitate (B), Observed in the Cladding of Gadolinia Rods of BWR-D, and (C)-(E) in Fuel Rods of BWR-A, $-C$, and $-B$, Respectively. Circled reflections in the SAD pattern of (A) denote hexagonal $\mathrm{Zr}(\mathrm{Fe}, \mathrm{Cr})_{2}$. 

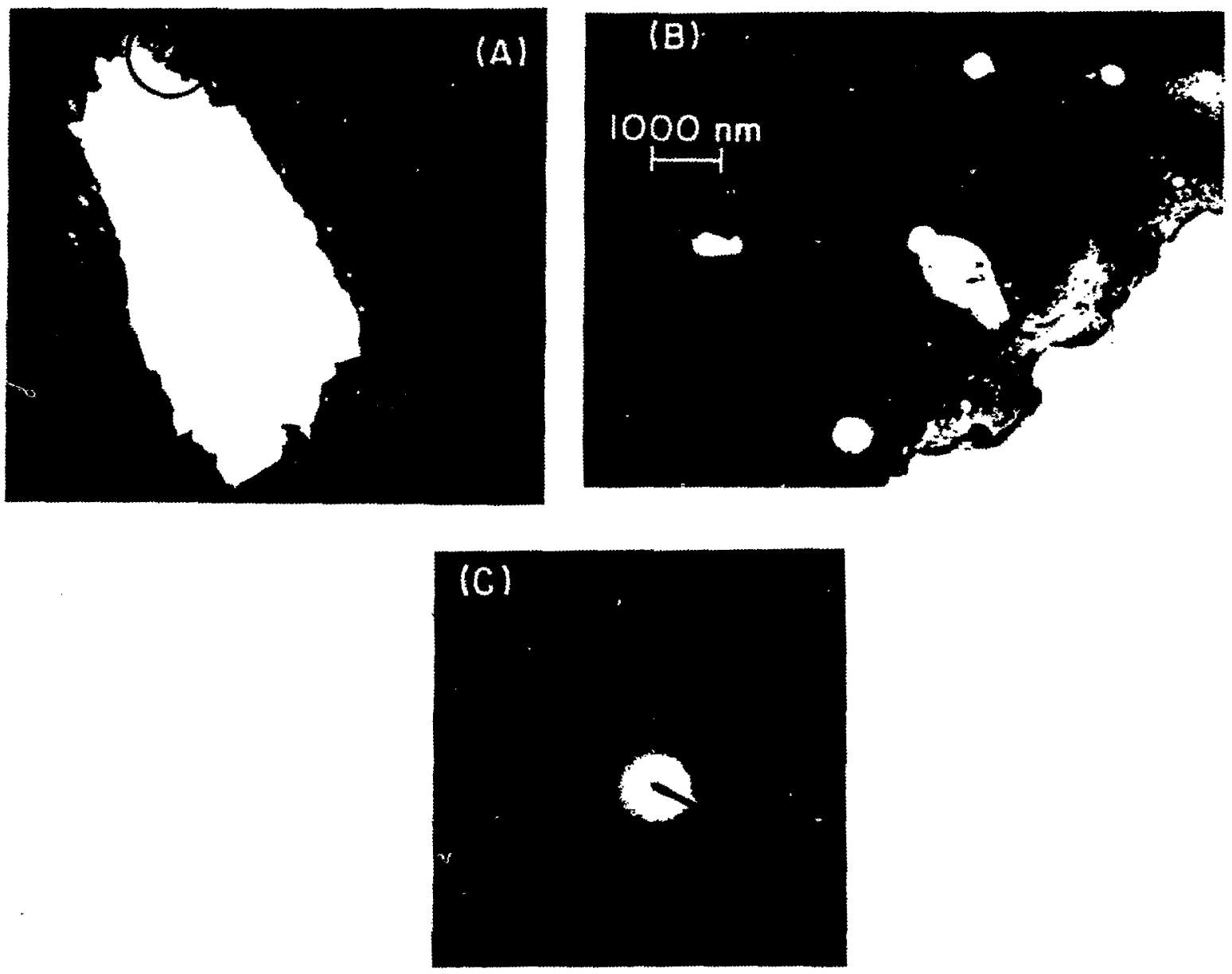

Fig. 10. Distribution (A) and Morphology (B) of Small Holes and Amorphized Local Regions Produced in TEM Specimens of PWR-A Cladding. The holes were produced as a result of preferential localized corrosion attack during jet-thinning near the amorphized and dissolved $\mathrm{Zr}(\mathrm{Fe}, \mathrm{Cr})_{2}$ precipitates. Diffraction pattern of the amorphous region is shown in (C). (D) shows $c$ component dislocations, apparently decorated by some kind of precipitates or defects, and a small $\mathrm{Zr}(\mathrm{Fe}, \mathrm{Cr})_{2}$ precipitate denoted with an arrow. 


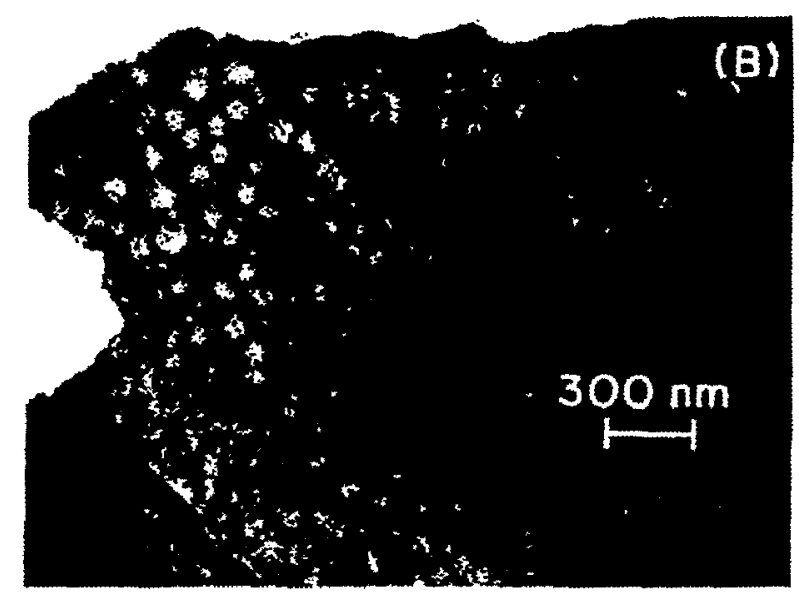

Fig. 11. Alternating Dark and Light Contrasts in a Bright-Field Image of PWR Cladding, Indicating an Irradiation-induced Spinodal-like Fluctuation of Local Solute Concentration following Complete Amorphization and Dissolution of the Intermetallic Precipitates.

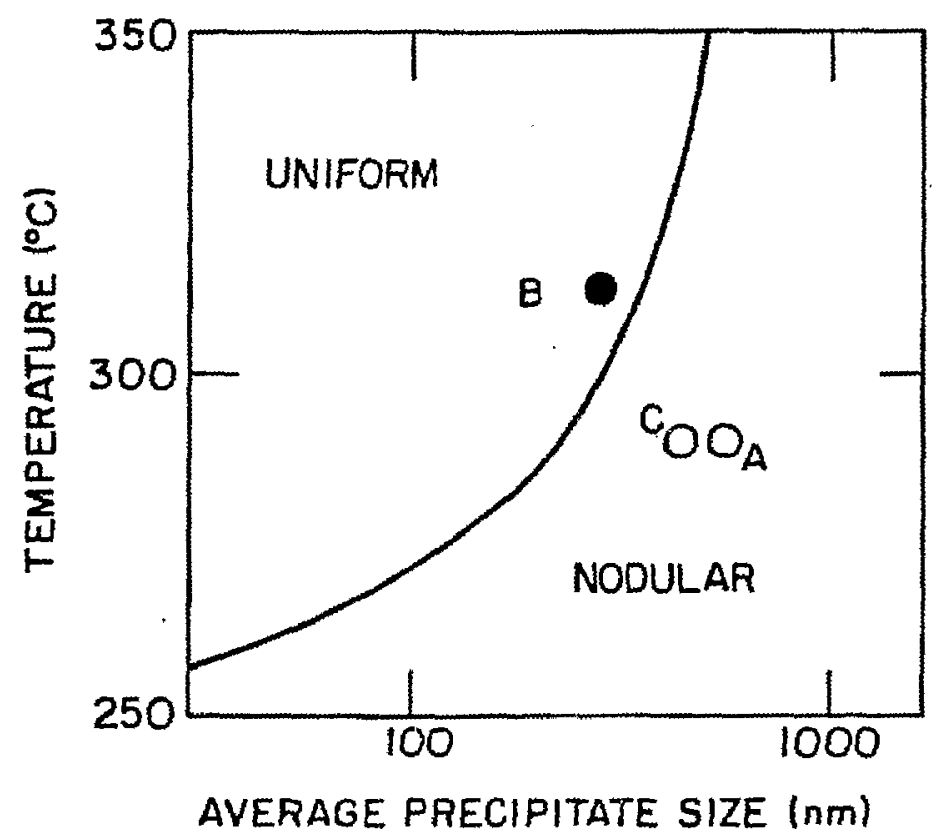

Fig. 12. Schematic Illustration of Expected Occurrence of Uniform and Nodular Oxidation in a BWR as a Function of Cladding Temperature and Average Size of Intermetallic Precipitates. 


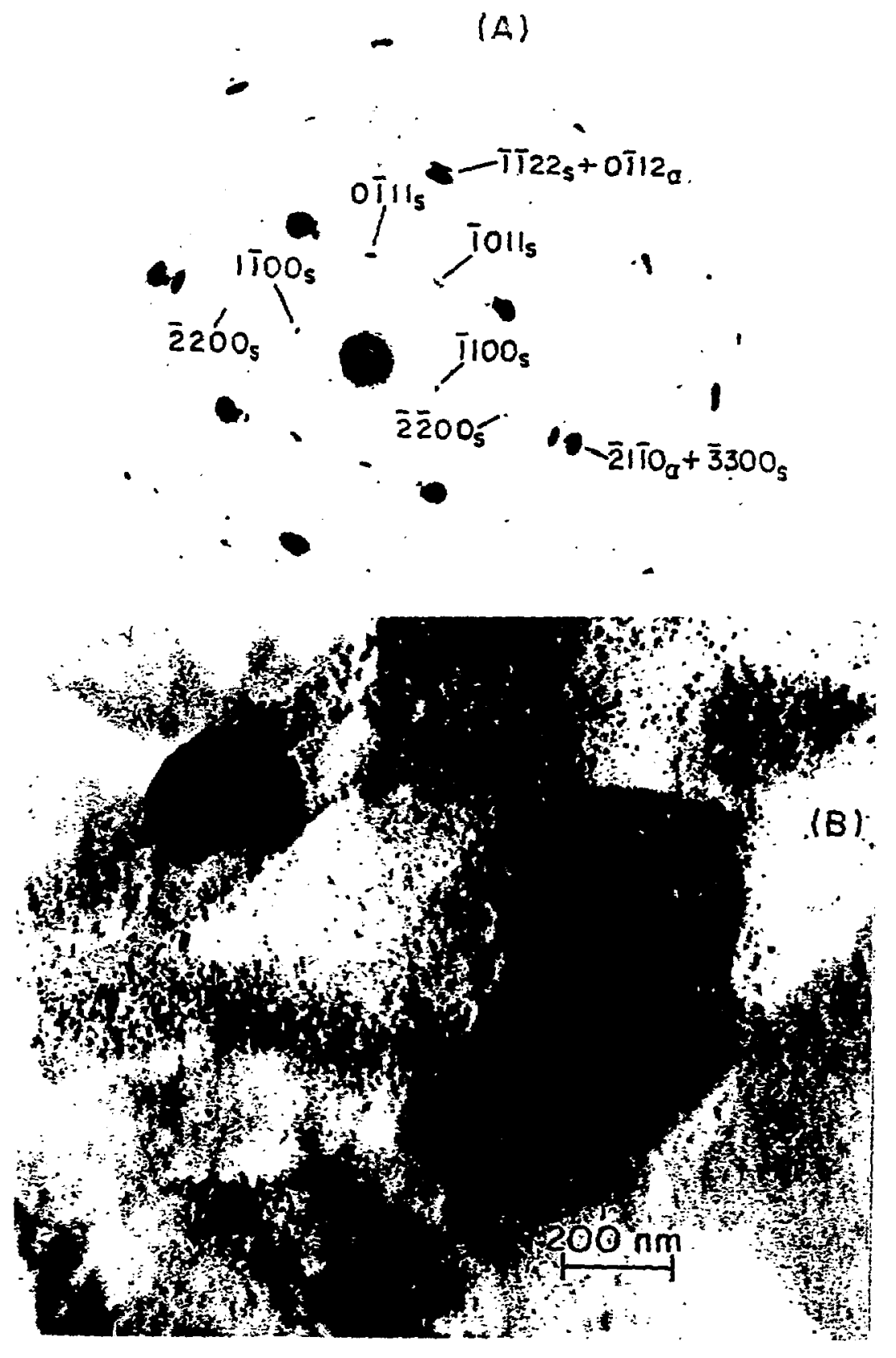

Fig. 13. SAD Patterns and Dark-Field Morphologies of $\mathrm{Z}_{3} \mathrm{O}$ Phase Observed in Fuel Cladding of BWR-B. (A) Indexed SAD pattern; (B) and $(C)$ dark-field images produced with (0111) and (1011) reflections of (A), tespectively; (D) SAD from another specimen; (E) dark-field image produced with (I10i) Reflection of (D) are shown. Subscripts " $\alpha$ " and "s" in (A) and (D) denotes, respectively, $\alpha-\mathrm{Zr}$ and $\mathrm{Zr}_{3} \mathrm{O}$ phase. 

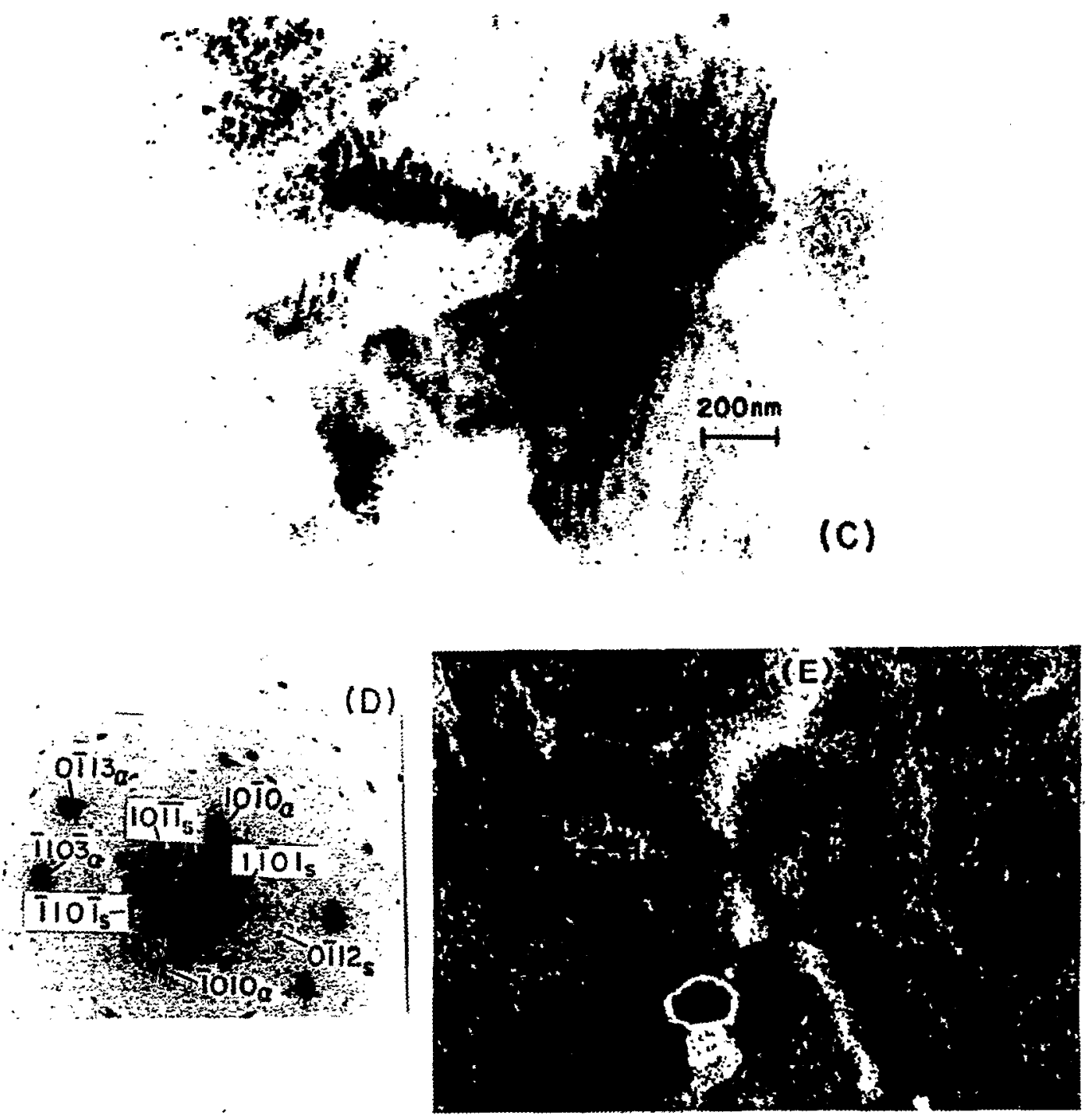

Fig. 13. Cont. 


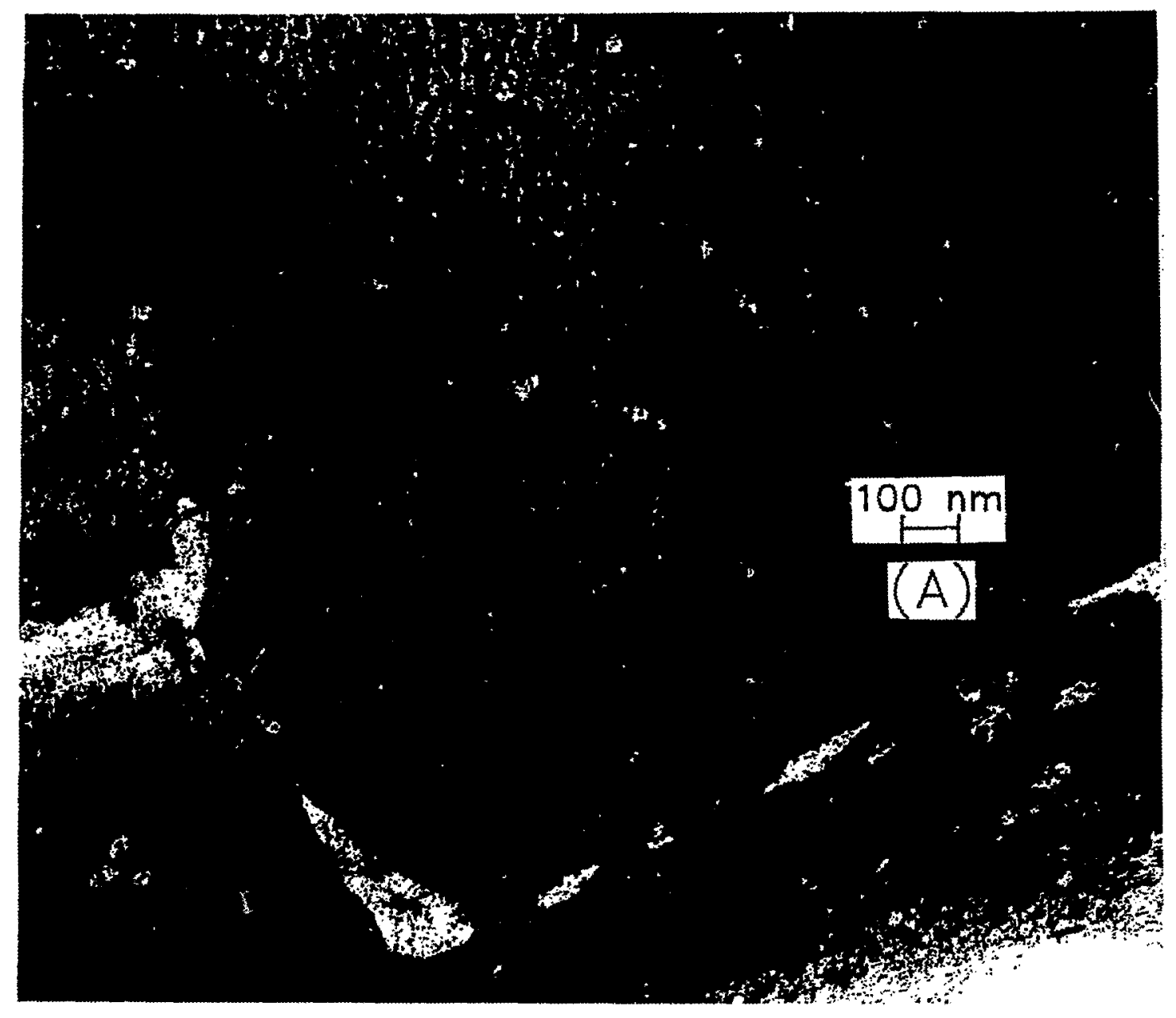

Fig. 14. Results of TEM Stereomicroscopy Analysis of Precipitates Observed in Zircaloy-2 Cladding from BWR-D Gadolinia Rod. (A) Bright-field image of a region selected for stereoanalysis; (B) and (C) bright-field stereopair images (in negative contrast) obtained from (A) for a tilt angle of 5 and $10^{\circ}$, respectively; (D) and (E) $S A D$ patterns of $(B)$ and $(C)$, respectively, showing reflections from $\alpha-\mathrm{Zr}$, cubic- $\mathrm{ZrO}_{2}, \delta$-hydride, surface-artifact hydride, and double diffraction, each denoted, respectively, by letter $\alpha, c, \delta, \chi$, and $D$; (F) identification of the 32 selected stereopair images of (B) and (C); (G) relative depth of the images of (F); (H) and (I) dark-field images produced from the (i1) reflections of cubic$\mathrm{ZrO}_{2}$ for tilt angles -3.1 and $5^{\circ}$, respectively, with some selected matching stereopair particles denoted with small circles; (J) enhanced stereopairs of the images selected in $(\mathrm{H})$ and $(\mathrm{I}) ;(\mathrm{K})$ identification of the 24 stereopair particles in the lower left circle of $(J)$; and (L) relative depth of the 24 stereopairs of $(K)$, showing more or less random bulk distribution. 


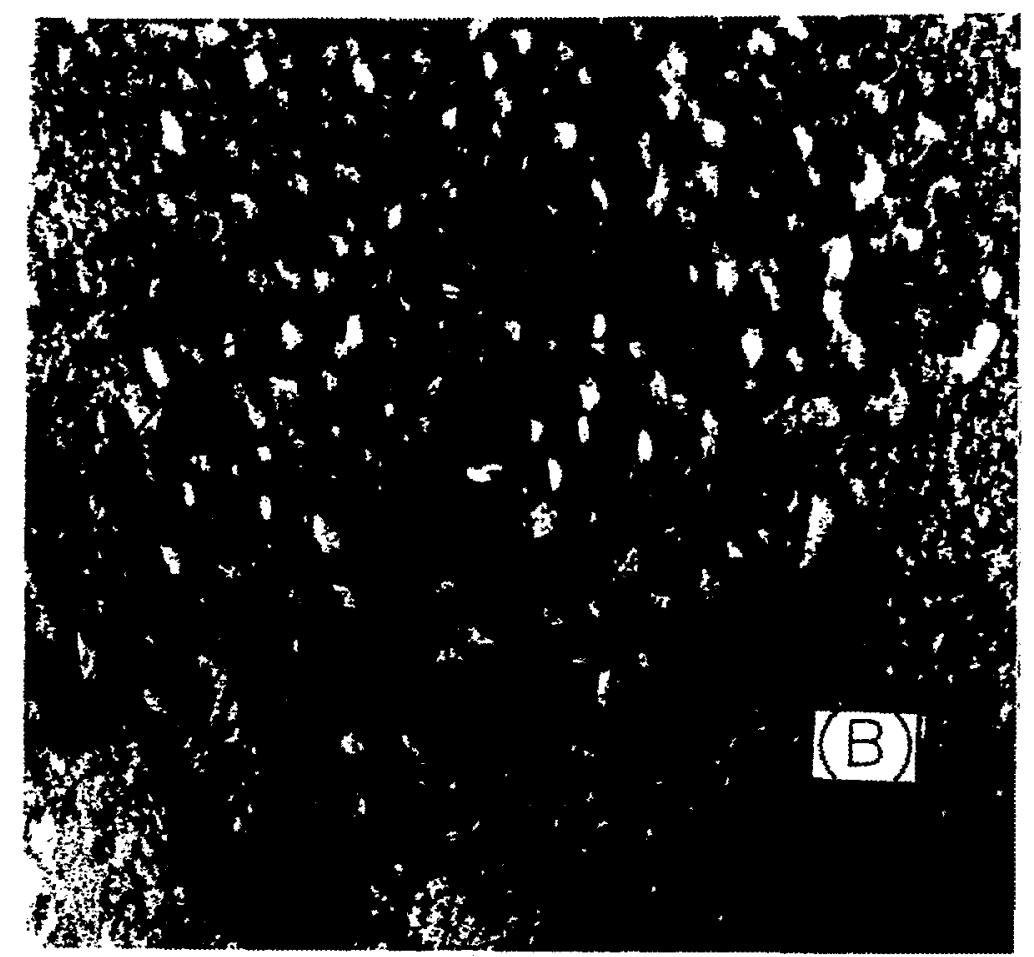

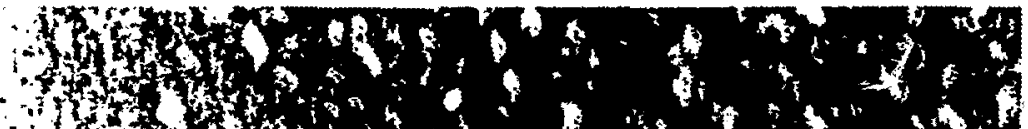

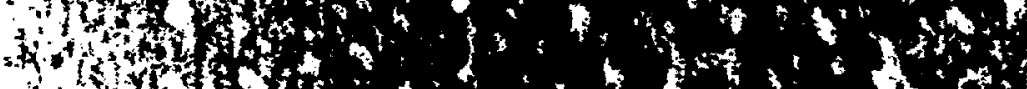

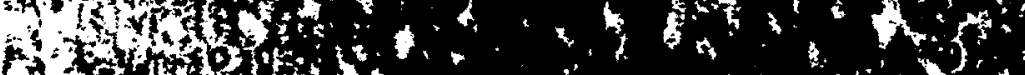

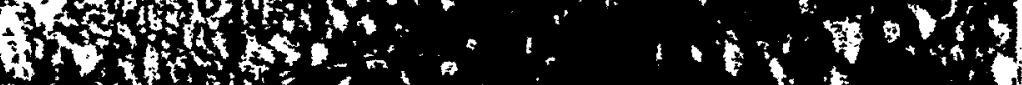

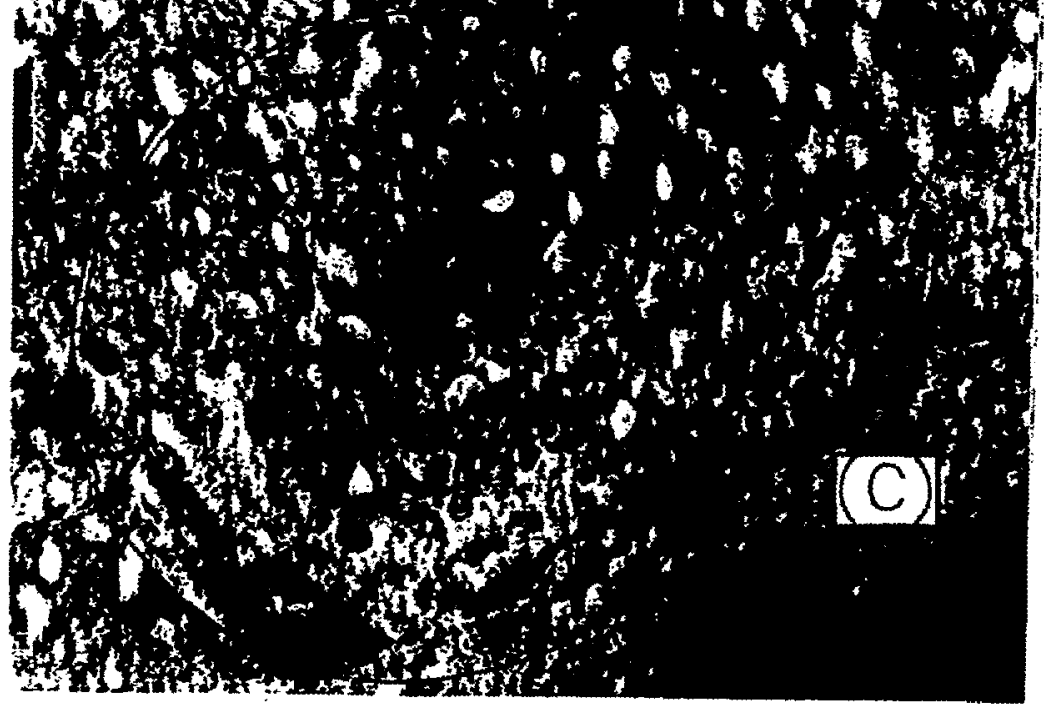

Fig. 14. Cont. 


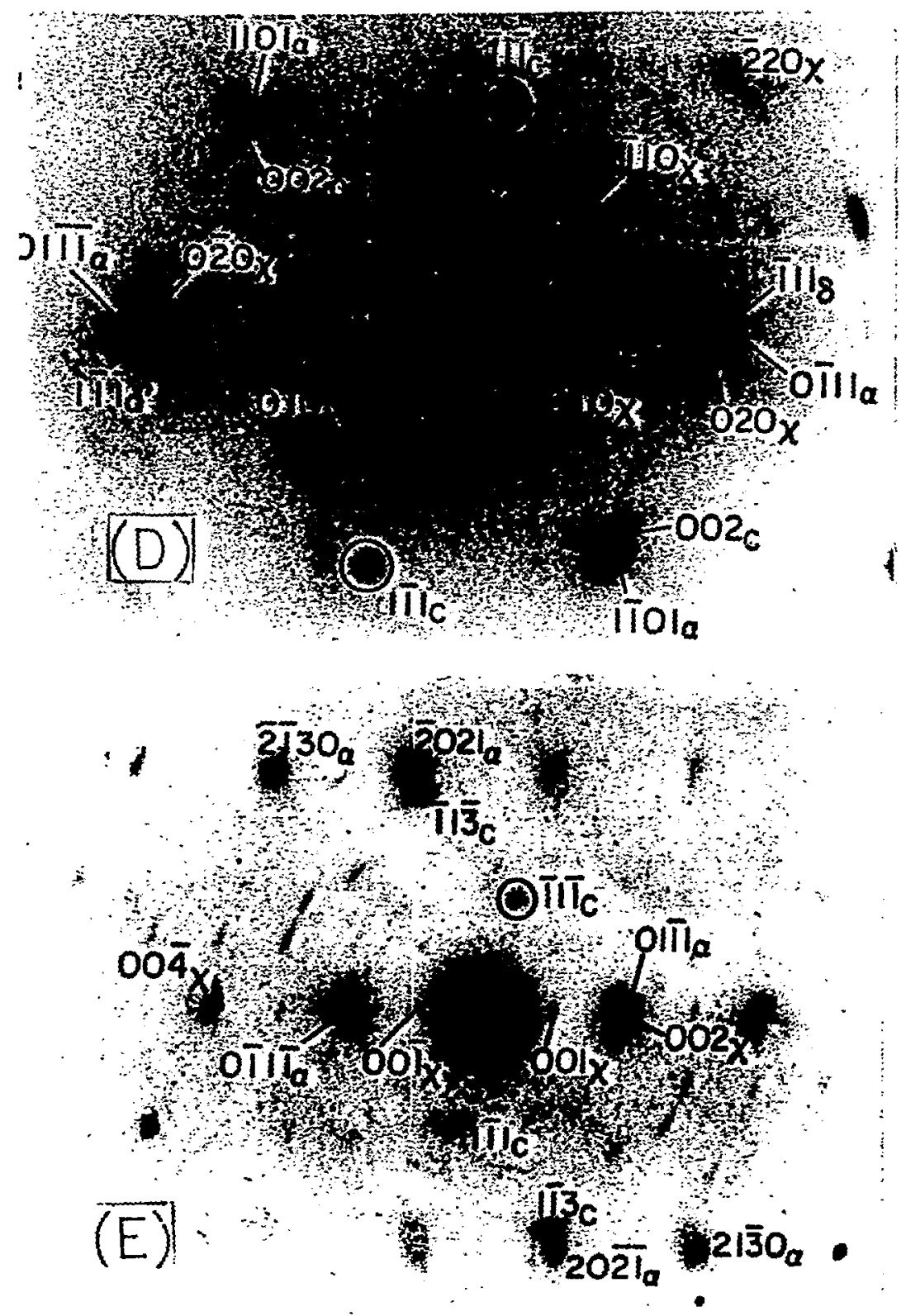

Fig. 14. Cont. 

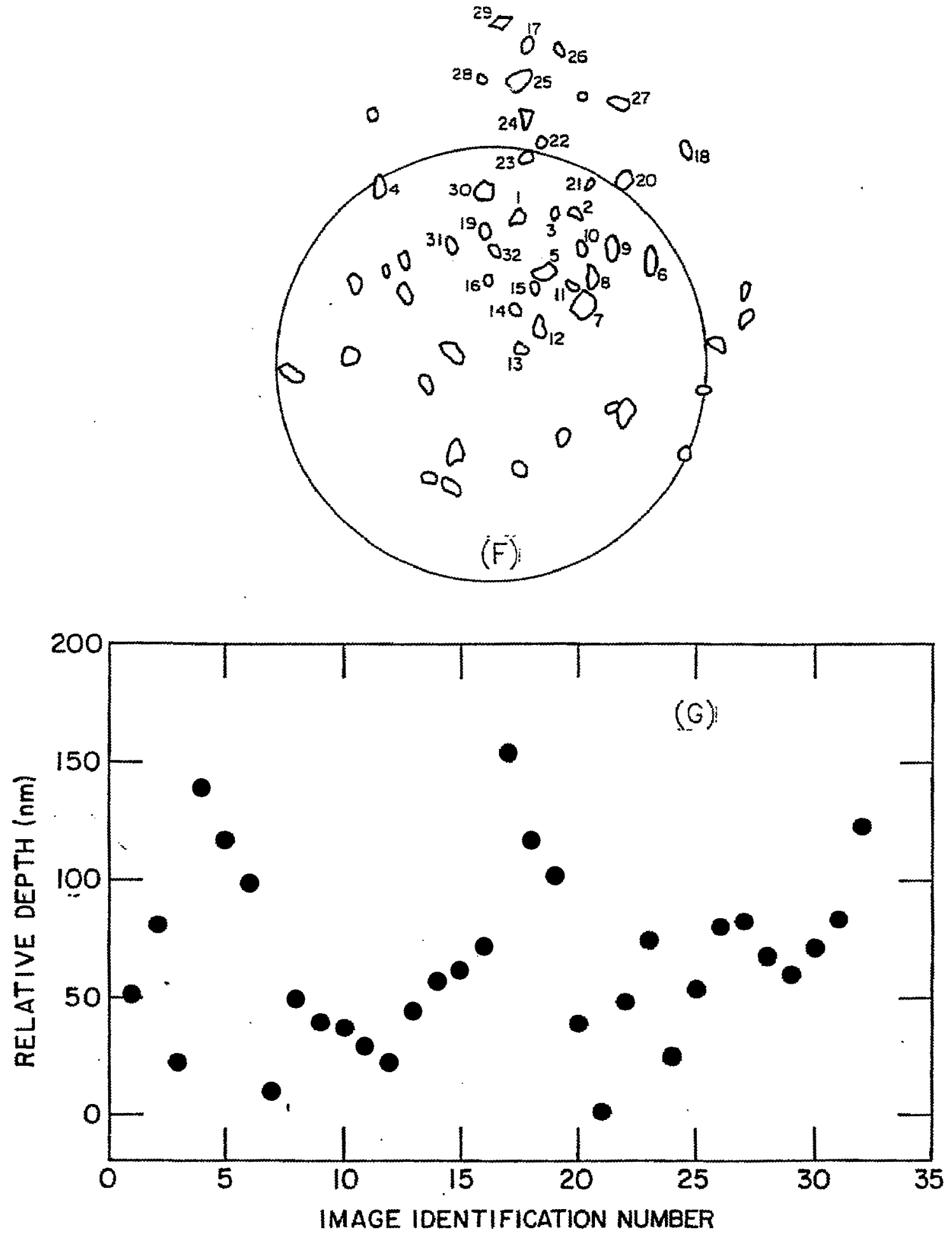

Fig. 14. Cont. 


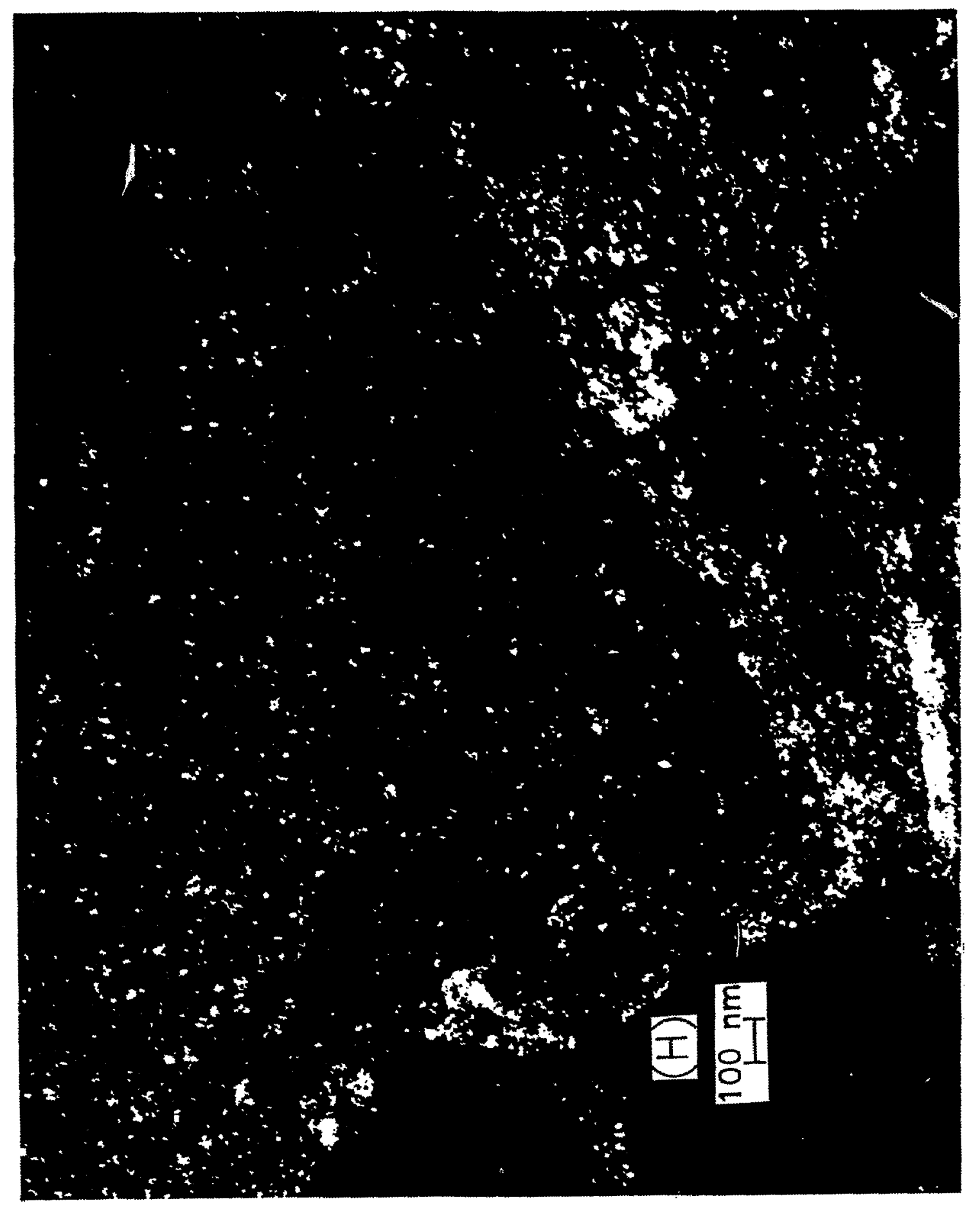




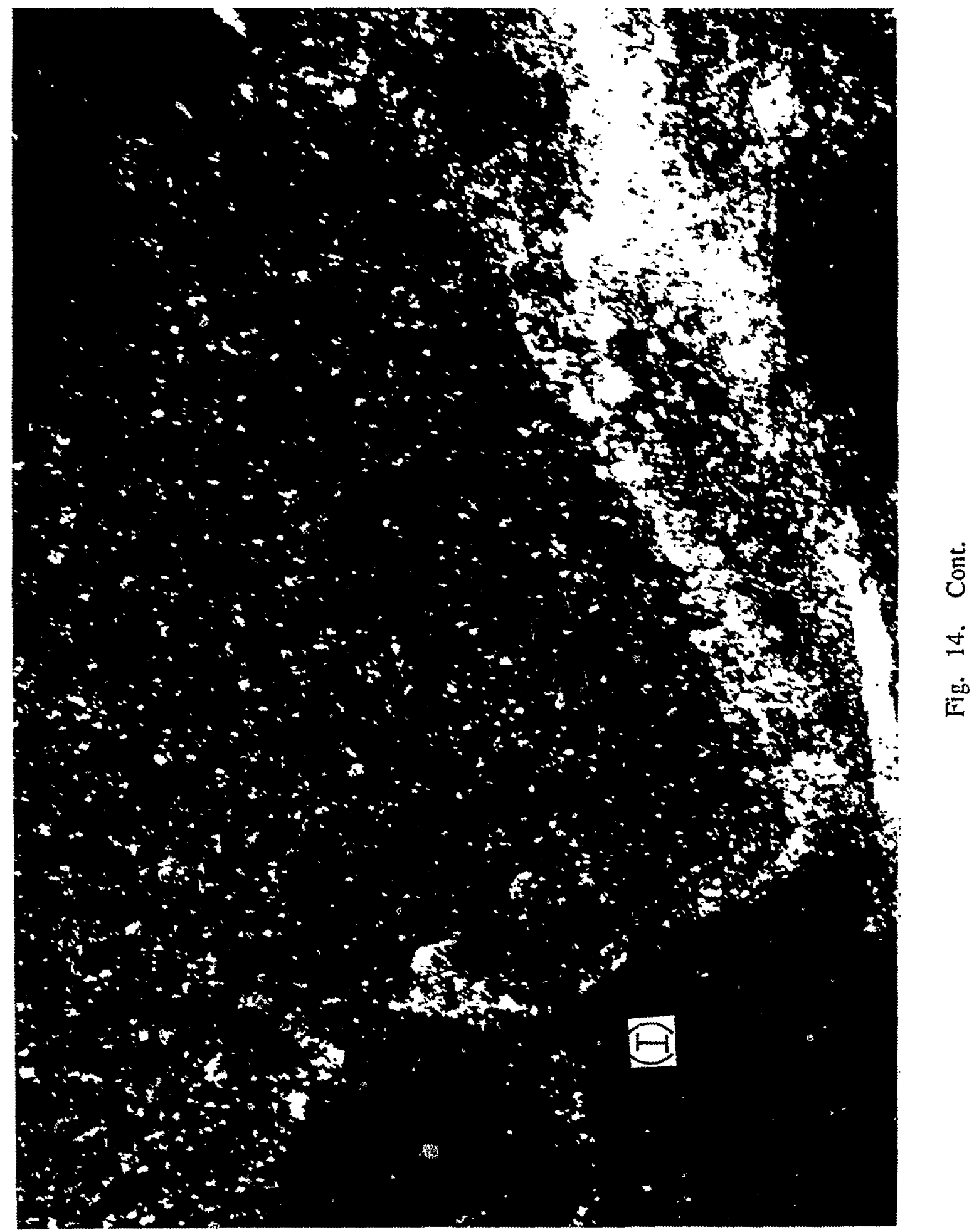




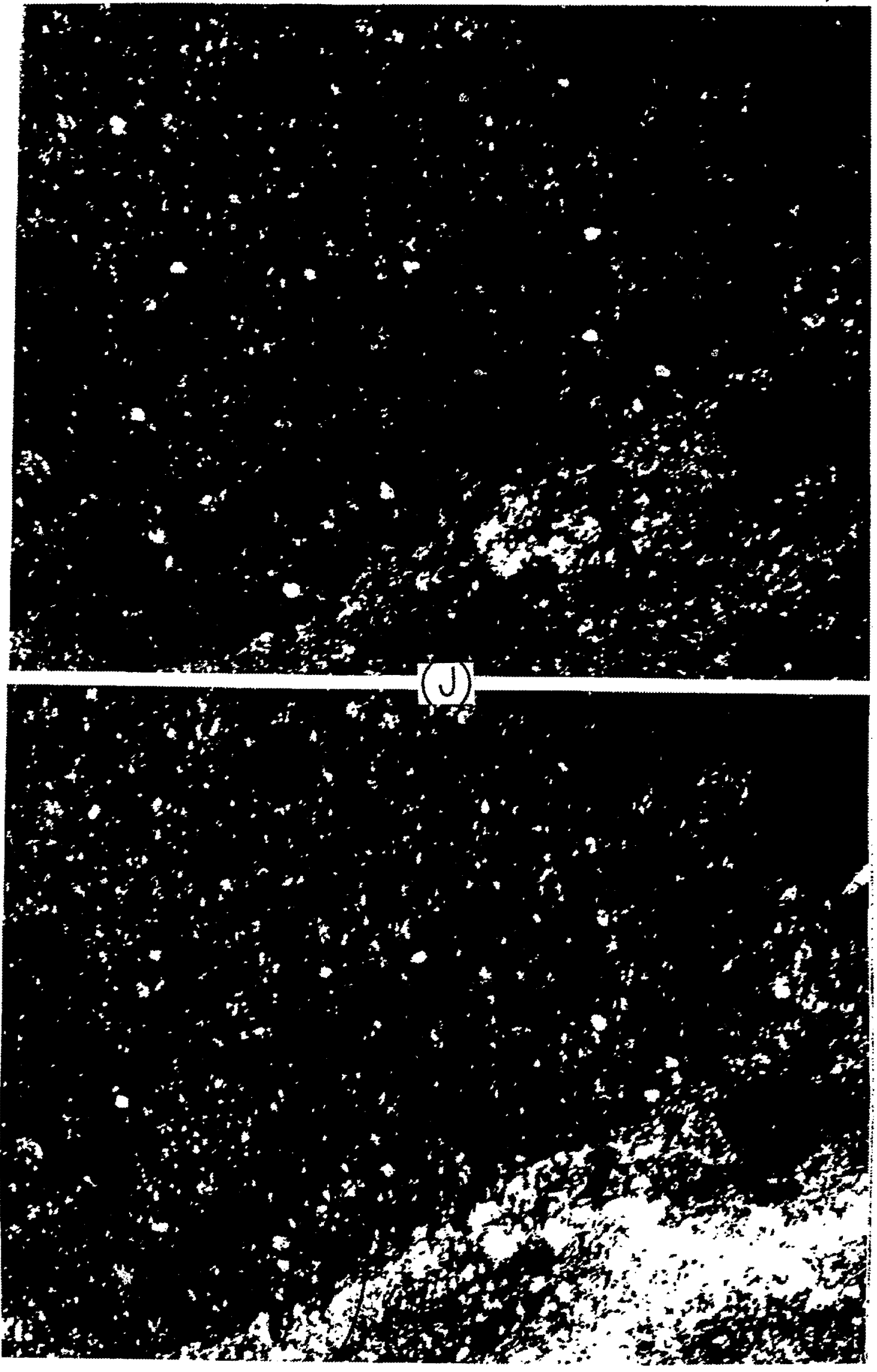

Fig. 14. Cont 

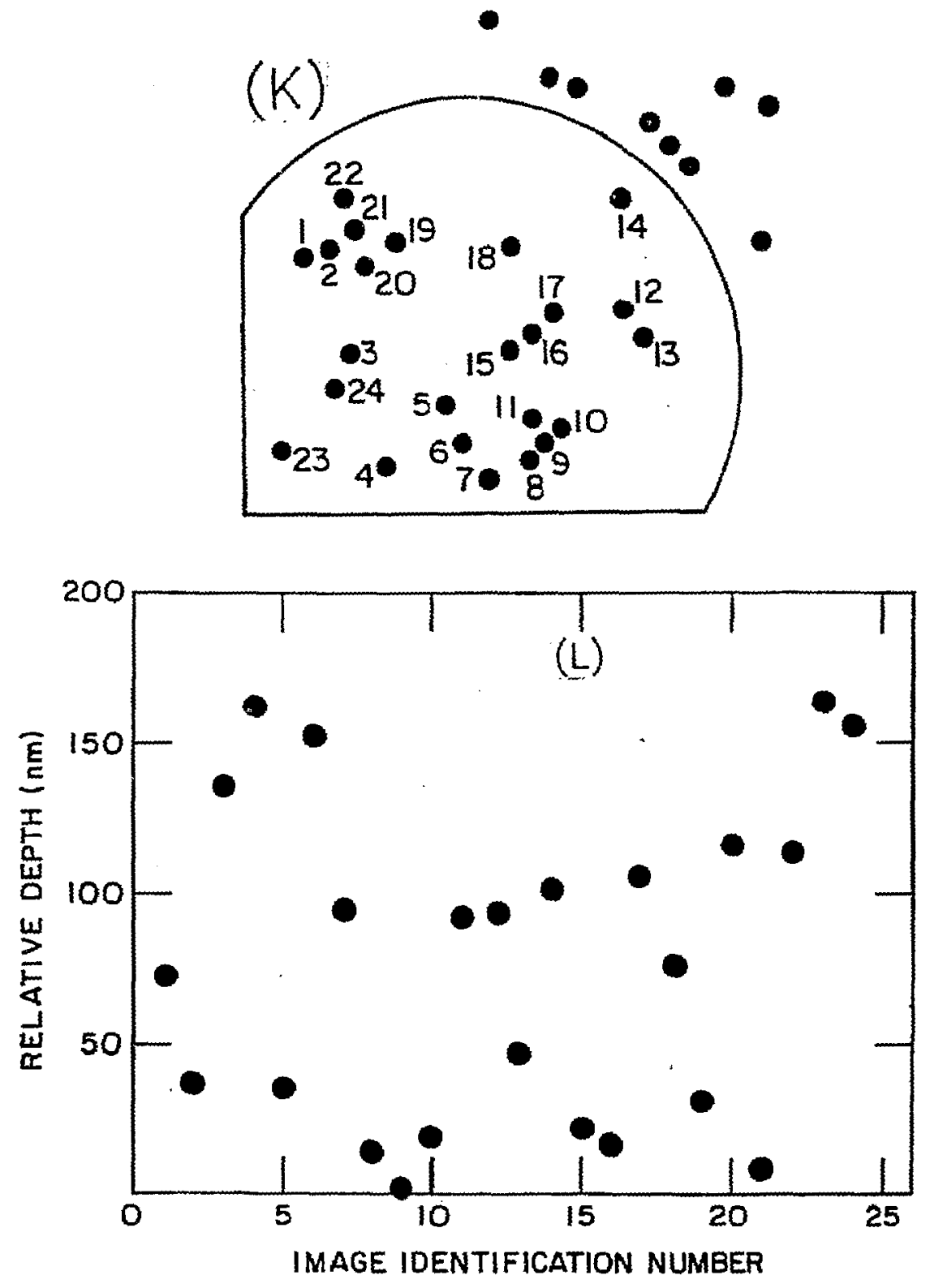

Fig. 14. Cont. 